\title{
Central Composite Design, Kinetic Model, Thermodynamics, and Chemical Composition of Pomelo (Citrus Maxima (Burm.) Merr.) Essential Oil Extraction by Steam Distillation
}

\author{
Tan Phat Dao $1,2,3, * \mathbb{C}$, Thanh Viet Nguyen ${ }^{1,3}$, Thi Yen Nhi Tran ${ }^{1,2,3} \mathbb{D}^{\text {, Xuan Tien Le }}{ }^{4,5}$, Ton Nu Thuy An ${ }^{3}$, \\ Nguyen Huu Thuan Anh ${ }^{3}$ and Long Giang Bach ${ }^{1,3, *}$ \\ 1 Institute of Environmental Technology and Sustainable Development, Nguyen Tat Thanh University, \\ Ho Chi Minh City 700000, Vietnam; ntviet@ntt.edu.vn (T.V.N.); ttynhi@ntt.edu.vn (T.Y.N.T.) \\ 2 Faculty of Enviromental and Food Engineering, Nguyen Tat Thanh University, \\ Ho Chi Minh City 700000, Vietnam \\ 3 Center of Excellence for Biochemistry and Natural Products, Nguyen Tat Thanh University, \\ Ho Chi Minh City 700000, Vietnam; tntan@ntt.edu.vn (T.N.T.A.); nhtanh@ntt.edu.vn (N.H.T.A.) \\ 4 Department of Chemical Engineering, Ho Chi Minh City University of Technology, 268 Ly Thuong Kiet Street, \\ District 10, Ho Chi Minh City 700000, Vietnam; tien.le@hcmut.edu.vn \\ 5 Vietnam National University-Ho Chi Minh City, Linh Trung Ward, Thu Duc District, \\ Ho Chi Minh City 700000, Vietnam \\ * Correspondence: dtphat@ntt.edu.vn (T.P.D.); blgiang@ntt.edu.vn (L.G.B.); Tel.: +84-988-889-072 (T.P.D.); \\ +84-969-294-297 (L.G.B.)
}

\section{check for} updates

Citation: Dao, T.P.; Nguyen, T.V.; Tran, T.Y.N.; Le, X.T.; An, T.N.T.; Anh, N.H.T.; Bach, L.G. Central Composite Design, Kinetic Model,

Thermodynamics, and Chemical Composition of Pomelo (Citrus Maxima (Burm.) Merr.) Essential Oil Extraction by Steam Distillation. Processes 2021, 9, 2075. https:// doi.org/10.3390/pr9112075

Academic Editor: Michaela Schmitz

Received: 21 October 2021

Accepted: 16 November 2021

Published: 19 November 2021

Publisher's Note: MDPI stays neutral with regard to jurisdictional claims in published maps and institutional affiliations.

Copyright: (c) 2021 by the authors. Licensee MDPI, Basel, Switzerland. This article is an open access article distributed under the terms and conditions of the Creative Commons Attribution (CC BY) license (https:// creativecommons.org/licenses/by/ $4.0 /)$.

\begin{abstract}
Pomelo peel-derived essential oils have been gaining popularity due to greater demand for stress relief therapy or hair care therapy. In this study, we first performed optimization of parameters in the pomelo essential oil extraction process on a pilot scale to gain better insights for application in larger scale production. Then extraction kinetics, activation energy, thermodynamics, and essential oil quality during the extraction process were investigated during the steam distillation process. Three experimental conditions including material mass, steam flow rate, and extraction time were taken into consideration in response surface methodology (RSM) optimization. The optimal conditions were found as follows: sample weight of $422 \mathrm{~g}$ for one distillation batch, steam flow rate of $2.16 \mathrm{~mL} / \mathrm{min}$ and extraction time of $106 \mathrm{~min}$ with the coefficient of determination $\mathrm{R}^{2}$ of 0.9812 . The nonlinear kinetics demonstrated the compatibility of the kinetic model with simultaneous washing and unhindered diffusion with a washing rate constant of $0.1515 \mathrm{~min}^{-1}$ and a diffusion rate constant of $0.0236 \mathrm{~min}^{-1}$. The activation energy of the washing and diffusion process was 167.43 $\mathrm{kJ} . \mathrm{mol}^{-1}$ and $96.25 \mathrm{~kJ} \cdot \mathrm{mol}^{-1}$, respectively. The thermodynamic value obtained at the $\Delta \mathrm{G}^{\circ}$ value was $-35.02 \mathrm{~kJ} \cdot \mathrm{mol}^{-1}$. The quality of pomelo peel essential oil obtained by steam distillation was characterized by its high limonene content (96.996\%), determined by GC-MS.
\end{abstract}

Keywords: Pomelo (Citrus maxima); CCD-RSM; kinetic model; activity energy; thermodynamic; GC-MS

\section{Introduction}

Pomelo (Citrus maxima (Burm.) Merr.) is a fruit tree widely grown in Vietnam and other parts around the world [1]. Pomelo is one of Vietnam's key fruit tree varieties. Its production has reached 433.9 thousand tons, increasing by $7.5 \%$, mainly in the Mekong Delta (according to the General Statistics Office 2019). As reported by the Ministry of Agriculture and Rural Development in the development of citrus fruit by 2020, the area planned for pomelo occupies the first place, up to 27,900 ha.

One of the problems when consuming pomelo is a very low percentage of edible parts (fruit pulp). This is a common feature of citrus fruits due to their thick exocarp which contributes to $20-50 \%$ of total weight. The pomelo by-products such as peels, seeds, 
and leaves that accrue during processing of the fruit have been drawing the attention of researchers due to their potential beneficial aspects in pharmaceutical, food, or cosmetic industries [2-4]. The extraction of essential oils is considered the main solution to utilize this by-product. There have been numerous attempts to recover essential oil from pomelo by-products by using a wide array of extraction methods including supercritical $\mathrm{CO}_{2}$ extraction, solvent-free microwave (SFME), and hydrodistillation (HD) $[5,6]$. It has been noted that types of extraction methods can significantly affect the number of oxidizing compounds in the essential oil [7]. Therefore, the selection of the appropriate method as well as the optimization of process parameters are also of great interest [8-10].

Process optimization and studying the kinetic model for the extraction process are important steps in scaling experimental production of essential oils to larger scale production. A number of kinetic studies have been conducted with regards to essential oil recovery on abundant agricultural materials. Milojević et al. investigated kinetics of distillation of juniper essential oil by adopting a two-parameter steady state diffusion model with a linear regression model proposal. The distillation process mechanism consists of two parts: (1) rapid distillation (washing stage) of volatile oil components on or near the surface, and (2) slow distillation or diffusion through plant tissues followed by the distillation from the outer surface of the raw material. The mathematical model is tested and evaluated by the dependence $\ln \left[\left(\mathrm{q}_{\mathrm{o}}-\mathrm{q}\right) / \mathrm{q}_{\mathrm{o}}\right]$ against time; the regression equation is applied on the first-order kinetic equation [11]. Desai et al. [12] carried out a modeling and optimization study to extract essential oils from lemongrass leaf by a classical method. Models are based on thermodynamic partitioning and kinetic desorption. The author used one-stage and two-stage desorption kinetics to describe the mechanism of the extraction process. The results indicated that a two-stage desorption model was suitable to describe the extraction state in which the rate constant was in the range of $0.1724-0.2623 \mathrm{~min}^{-1}$ in case of rapid extraction and $0.007-0.0577 \mathrm{~min}^{-1}$ in the fractional fraction. The data fit also indicated that extraction was controlled by the intracellular diffusion. Milojević et al. further refined and justified the appropriateness of the kinetic models in water and steam distillation processes [13]. Experimental data were obtained by studying the hydro-distillation kinetics of essential oils from juniper berries. A physical model based on simultaneous washing and diffusion of essential oils from plant materials was developed to describe the kinetics of essential oil hydrolysis, and two other simple models were derived from the physical model. This assumes immediate washing followed by diffusion or diffusion without washing (i.e., first-order kinetics). All three models described the experimental kinetic data of the distillation process well regardless of distillation apparatus type and its size, type of plant material, and operating conditions. Later attempts to further develop the phenomenological kinetic models adopts the three-stage mechanism that assumes three phases occurring simultaneously: washing, unhindered diffusion, and hindered diffusion [14,15]. Compared with well-known kinetic models, this kinetic model was considered a suitable one for the extraction of essential oil from juniper berries. Moreover, the model has been tested on some other plant materials. The authors recommended using this method to model the kinetics of the extraction of essential oils from some plant materials by both classical and microwave-assisted methods. Indeed, the kinetics models of extracts from various plant materials using a model that assumes washing and diffusion (unhindered diffusion, hindered diffusion) are the basis used to describe the time change of essential oil extraction performance. The models are simple to apply with relatively high accuracy and can be used in essential oil extraction techniques in production process practices.

The biggest challenge in scaling pilot-scale models into industrial processes is the choice of solvent and extraction method. To the best of our knowledge, the kinetics, thermodynamics and optimization process have not been explored in the steam distillation process of pomelo peels. In this study, pomelo peel essential oil was extracted by the steam distillation process which is considered a green method and can be used to improve the current industrial extraction processes. The experimental data on the extraction process was modeled according to Milojević et al. [14,15]. In addition, other aspects of activation 
energy such as thermodynamics are also important in the process of extracting essential oils from pomelo peels. Therefore, we performed an optimization process through the integrated central composite design in the response surface methodology (CCD-RSM), determined a suitable kinetic model to describe the extraction process, parameters of the Arrhenius equation, and the thermodynamic parameters of the extraction process. Chemical composition analysis was also carried out to evaluate the quality of essential oils from pomelo peels. The results are expected to aid in the development of industrial oil extraction processes and contribute to reduction of agricultural waste.

\section{Materials and Methods}

\subsection{Materials}

Pomelo (C. maxima) fruit of the Da Xanh variety was collected in the Ben Tre province, Mekong Delta of Vietnam (latitudes $10^{\circ} 14^{\prime} 54^{\prime \prime} \mathrm{N}$ and longitudes $106^{\circ} 22^{\prime} 34^{\prime \prime} \mathrm{E}$ ) in July 2021. After being selected, fruits are preliminarily treated and peeled off (the number of peels obtained is $15-20 \% v / w$, including: flavedo and albedo). The pomelo flavedo was manually peeled off to be prepared for subsequent experiments. Fresh ingredients were used in all experiments.

\subsection{Extraction of Pomelo Essential Oil}

\subsubsection{Steam Distillation}

The peeled pomelo flavedo was ground to obtain maximum extraction efficiency [16]. A sample of 300-900 $\mathrm{g}$ with $800 \mathrm{~mL}$ of water was subjected to the distillation system (Figure 1). The flask containing the sample mixture was connected with steam distillation with a modified Clevenger apparatus, and a condenser was placed on the top to capture the extracted essential oil. The process was operated at a flow rate of $2.4 \mathrm{~mL} / \mathrm{min}$ until an unchangeable amount of essential oil was attained. The extraction was performed for 10 min over several cycles to assess the extraction kinetics.

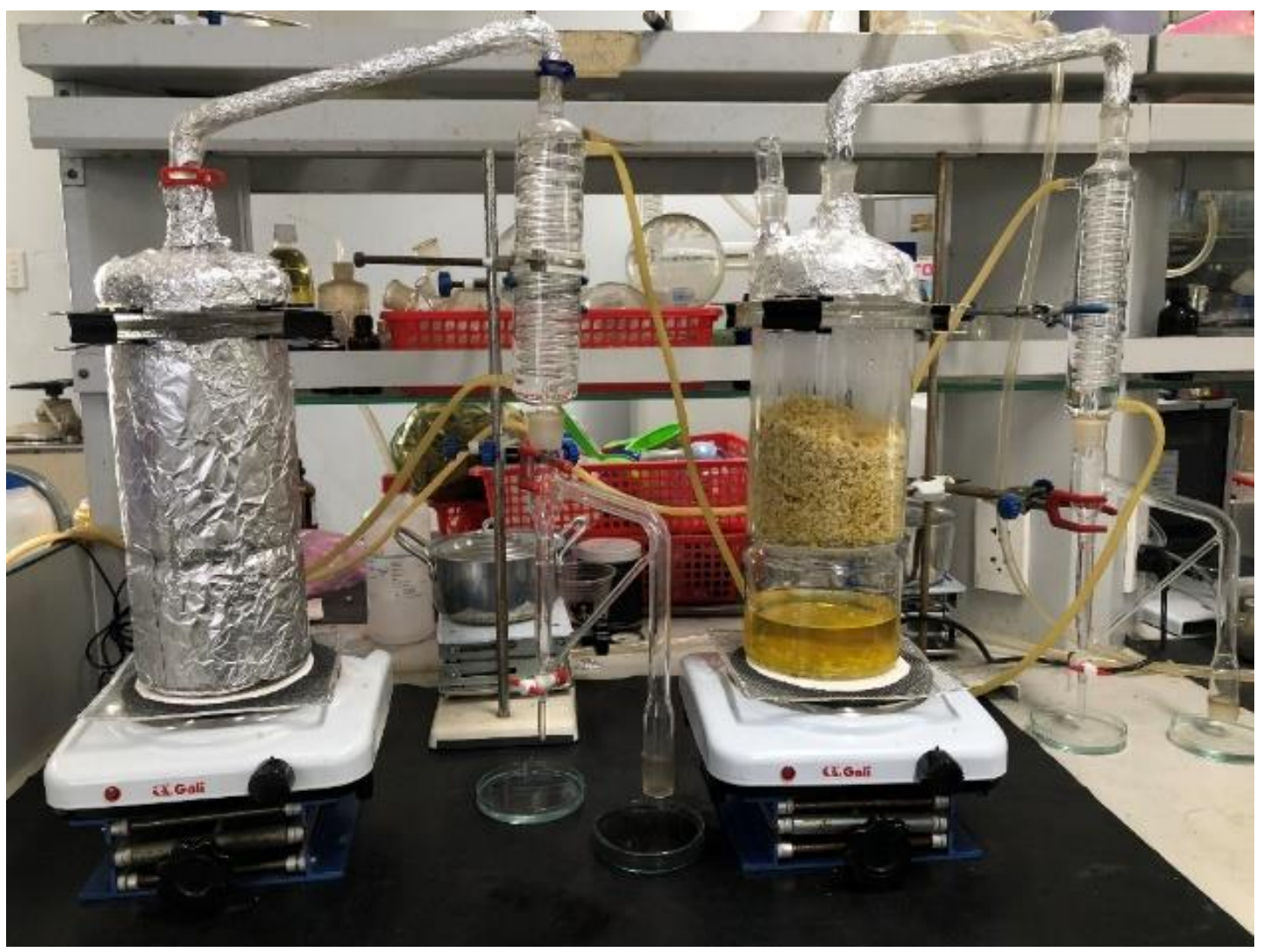

Figure 1. Steam distillation system. 
The design parameters for the single-factor survey were (a) input weight: 300, 500, 700, $900 \mathrm{~g}$; (b) steam flow rate: 1.8, 2.1, 2.4, $3.4 \mathrm{~mL} / \mathrm{min}$ corresponding to system feed temperature of $120,130,140,150{ }^{\circ} \mathrm{C}$, and (c) extraction time from starting to reaching the saturation stage of essential oil.

The amount of essential oil (mL of essential oil per $100 \mathrm{~g}$ of dry material) is calculated according to Equation (1):

$$
\mathrm{Y}\left(\%, \frac{\mathrm{mL}}{100 \mathrm{~g}}\right)=\frac{\mathrm{V}_{\mathrm{EO}}}{\mathrm{m}_{\mathrm{used}} \times(100-\mathrm{h})} \times 100 \times 100
$$

where $\mathrm{Y}$ is the yield, the content of essential oil obtained per $100 \mathrm{~g}$ of dry material, $\mathrm{V}_{\mathrm{EO}}$ is the volume of essential oil obtained in the extraction process, $\mathrm{m}_{\mathrm{used}}$ is mass of raw materials, and $h$ is the moisture content of the material. The first 100 coefficient is of the moisture function and the second 100 coefficient is of the efficiency at 100 (g) of material.

\subsubsection{Optimized by RSM}

In this study, we used response surface methodology (RSM, Design Expert 11 software) as an optimization tool to perform experimental design, statistical processing, and to determine optimal extraction conditions. Values such as material mass (A), steam flow rate (B), and extraction time (C) were established based on the best conditions of the previous single-factor survey. The central composite design (CCD) design is an integrated tool that is more commonly used than other designs in terms of both good experimental design and the lack of operating equipment restrictions $[17,18]$. The experiments were designed by CCD including 5 levels $-\alpha,-1,0,+1$, and $+\alpha$, and the set-up of 20 experiments with three factors are shown in Table 1. Statistical values and the values of model's expectations are considered measures to be able to optimize the model.

Table 1. Experimental design table with three factors according to CCD of RSM.

\begin{tabular}{|c|c|c|c|c|c|c|c|c|c|}
\hline \multirow{2}{*}{ No. } & \multicolumn{3}{|c|}{ Code } & \multirow{2}{*}{$\mathrm{Y}(\%, \mathrm{~mL} / 100 \mathrm{~g})$} & \multirow{2}{*}{ No. } & \multicolumn{3}{|c|}{ Code } & \multirow{2}{*}{$\mathrm{Y}(\%, \mathrm{~mL} / 100 \mathrm{~g}$} \\
\hline & A & B & $\mathrm{C}$ & & & $\mathbf{A}$ & B & $\mathrm{C}$ & \\
\hline 1 & -1 & -1 & -1 & & 11 & 0 & $-\alpha$ & 0 & \\
\hline 2 & -1 & -1 & +1 & & 12 & 0 & $+\alpha$ & 0 & \\
\hline 3 & -1 & +1 & -1 & & 13 & 0 & 0 & $-\alpha$ & \\
\hline 4 & -1 & +1 & +1 & & 14 & 0 & 0 & $+\alpha$ & \\
\hline 5 & +1 & -1 & -1 & & 15 & 0 & 0 & 0 & \\
\hline 6 & +1 & -1 & +1 & & 16 & 0 & 0 & 0 & \\
\hline 7 & +1 & +1 & -1 & & 17 & 0 & 0 & 0 & \\
\hline 8 & +1 & +1 & +1 & & 18 & 0 & 0 & 0 & \\
\hline 9 & $-\alpha$ & 0 & 0 & & 19 & 0 & 0 & 0 & \\
\hline 10 & $+\alpha$ & 0 & 0 & & 20 & 0 & 0 & 0 & \\
\hline
\end{tabular}

Where, $A$ is the material mass $(\mathrm{g}), \mathrm{B}$ is the steam flow rate $(\mathrm{mL} / \mathrm{min})$, and $\mathrm{C}$ is extraction time (min).

\subsubsection{Kinetics of Essential Oil Extraction}

The kinetics of essential oil extraction reflect the desorption of the essential oil from the batch over time. In steam distillation, the process is closely dependent on factors such as mass, steam flow rate, and extraction time, which significantly affect the desorption kinetics of any material. Therefore, the contact time at which the desorption process reaches the state is actually determined according to these factors.

In the batch desorption system, models describing the solubility of the essential oil from the surface and diffusing the essential oil within the materials were developed to explain the desorption kinetics of the extraction process. The pseudo-first model with nonlinear regression is widely used with high compatibility to explain the mechanism of the process in solid-liquid interaction $[14,15,19,20]$.

Kinetic models are based on two main mechanisms: 
(1) Washing: essential oil obtained from the surface of raw materials

(2) Diffusion: essential oil is diffused from the inside of the material to the surface of the material, which comprises two processes described as follows. The first one is unhindered diffusion, involving in a broken vesicle of essential oils, unimpeded by membranes or other barriers presented in the material; the second one is hindered fiffusion, involving in the transfer of essential oils across the membrane which is intact, not disrupted.

From here, hypotheses are built based on the mechanism of the extraction process and generated pseudo models. These models are applied to describe the kinetics of pomelo peel essential oil extraction. The models are formed based on the coefficient of determination $\left(R^{2}\right)$ and the error values must be minimal for determination of the most suitable model. Model of simple diffusion without washing:

$$
\frac{\mathrm{q}}{\mathrm{q}_{\infty}}=1-\mathrm{e}^{-\mathrm{k}_{1} \mathrm{t}}
$$

Model of instantaneous washing followed by diffusion:

$$
\frac{\mathrm{q}}{\mathrm{q}_{\infty}}=1-\left(1-\mathrm{f}_{\mathrm{w}}\right) \times \mathrm{e}^{-\mathrm{k}_{\mathrm{d} 1} \mathrm{t}}
$$

Model of simultaneous washing and unhindered diffusion:

$$
\frac{\mathrm{q}}{\mathrm{q}_{\infty}}=1-\mathrm{f}_{\mathrm{w}} \times \mathrm{e}^{-\mathrm{k}_{\mathrm{w}} \mathrm{t}}-\left(1-\mathrm{f}_{\mathrm{w}}\right) \times \mathrm{e}^{-\mathrm{k}_{\mathrm{d} 1} \mathrm{t}}
$$

Model of simultaneous washing, unhindered diffusion, and hindered diffusion:

$$
\frac{\mathrm{q}}{\mathrm{q}_{\infty}}=1-\mathrm{f}_{\mathrm{w}} \times \mathrm{e}^{-\mathrm{k}_{\mathrm{w}} \mathrm{t}}-\mathrm{f}_{\mathrm{d} 1} \times \mathrm{e}^{-\mathrm{k}_{\mathrm{d} 1} \mathrm{t}}-\mathrm{f}_{\mathrm{d} 2} \times \mathrm{e}^{-\mathrm{k}_{\mathrm{d} 2} \mathrm{t}}
$$

where,

$f_{w}, f_{d 1}, f_{d 2}$ : the fractions of the essential oil extracted via washing, unhindered difusion and hidered diffusion.

$\mathrm{k}_{\mathrm{w}}, \mathrm{k}_{\mathrm{d} 1}, \mathrm{k}_{\mathrm{d} 2}\left(\mathrm{~min}^{-1}\right)$ : the rate constants for washing, unhindered diffusion, and hindered diffusion.

$\mathrm{q}_{\infty}, \mathrm{q}(\mathrm{mL} / 100 \mathrm{~g})$ : the amount of essential oils obtained during the desorption process at equilibrium and any time $t(\mathrm{~min})$.

\subsubsection{Statistical Evaluation}

An error function assessment is required to evaluate the fit of the equations to the experimental results. In the present study, the coefficient of determination $\left(R^{2}\right)$ and the percentage $(\% q)$ were used to quantitatively compare the applicability of each model.

$$
\begin{gathered}
R^{2}=1-\frac{\sum_{i=1}^{\mathrm{N}}\left(\mathrm{q}_{\infty, \text { exp }}-\mathrm{q}_{\infty, \text { cal }}\right)^{2}}{\sum_{\mathrm{i}=1}^{\mathrm{N}}\left(\mathrm{q}_{\infty, \text { exp }}-\mathrm{q}_{\infty, \text { mean }}\right)^{2}}=\frac{\sum_{\mathrm{i}=1}^{\mathrm{N}}\left(\mathrm{q}_{\infty, \text { exp }}-\mathrm{q}_{\infty, \text { mean }}\right)^{2}}{\sum_{\mathrm{i}=1}^{\mathrm{N}}\left(\mathrm{q}_{\infty, \text { cal }}-\mathrm{q}_{\infty, \text { mean }}\right)^{2}+\sum_{\mathrm{i}=1}^{\mathrm{N}}\left(\mathrm{q}_{\infty, \mathrm{cal}}-\mathrm{q}_{\infty, \exp }\right)^{2}} \\
\% \mathrm{q}=\frac{\mathrm{q}_{\infty, \exp }-\mathrm{q}_{\infty, \text { cal }}}{\mathrm{q}_{\infty, \exp }} \times 100
\end{gathered}
$$

where,

$\mathrm{q}_{\infty, \exp }(\mathrm{mL} / 100 \mathrm{~g})$ : is the amount of essential oil obtained in the experiment; 9 software;

$\mathrm{q}_{\infty, \text { cal }}(\mathrm{mL} / 100 \mathrm{~g})$ : is the amount of essential oil obtained from the model using Origin

$\mathrm{q}_{\infty}$, mean $(\mathrm{mL} / 100 \mathrm{~g})$ : is the average value of $\mathrm{q}_{\infty}$; and

$\mathrm{N}$ : the number of data points. 
All experiments were repeated in triplicate and presented as standard deviations. The standard deviation of the results is calculated using Microsoft Excel. Optimization is designed on Design Expert 11 software. Study kinetics, thermodynamics, and show related graphs are designed through Origin 9.0 software.

\subsubsection{Analysis of Essential Oil}

Chemical composition of the pomelo fruit oil was determined by gas chromatographymass spectrometry (GC-MS) analysis using GC Agilent $6890 \mathrm{~N}$ instrument coupled with HP5-MS column $(30 \mathrm{~m} \times 0.25 \mathrm{~mm}$, film thickness $0.25 \mu \mathrm{m}$, Agilent Technologies, Santa Clara, CA, USA) and MS 5973 inert. The pressure of the head column was 9.3 psi. A volume of $25 \mu \mathrm{L}$ of essential oil was included with $1.0 \mathrm{~mL}$ n-hexane. GC-MS system operated at the following conditions: carrier gas $\mathrm{He}$, the flow rate at $1.0 \mathrm{~mL} / \mathrm{min}$, and injection volume $1.0 \mu \mathrm{L}$. The injector temperature was set at $250^{\circ} \mathrm{C}$ and the split ratio of 1:50. The thermal program for samples was set at: $50{ }^{\circ} \mathrm{C}$ kept for $2 \mathrm{~min}$, increased by $2{ }^{\circ} \mathrm{C} / \mathrm{min}$ to $80^{\circ} \mathrm{C}$, continued to increase by $5^{\circ} \mathrm{C} / \mathrm{min}$ to $150^{\circ} \mathrm{C}$ and $10^{\circ} \mathrm{C} / \mathrm{min}$ to $200^{\circ} \mathrm{C}$, and finally increased by $20^{\circ} \mathrm{C} / \mathrm{min}$ to $300^{\circ} \mathrm{C}$ with the holding time of $5 \mathrm{~min}$.

Identification of the constituents was carried out by comparing the obtained retention indices and mass spectrum with the data of NIST Chemistry WebBook.

\section{Results and Discussion}

\subsection{Effect of Facctors on Extraction by Steam Distillation}

Among the parameters affecting the steam distillation process, the mass of the raw material is considered one of the main influencing factors, as appropriate mass ensures that the amount of steam can attract all the essential oils in the steam distillation. At the laboratory scale, the glass apparatus contains a maximum weight of $900 \mathrm{~g}$ of material, thereby it is set as the upper limit of this experiment. Experiments were performed at different sample weights (including $300 \mathrm{~g}, 500 \mathrm{~g}$, $700 \mathrm{~g}$, and $900 \mathrm{~g}$ ), and extracted at different times from 10 to $120 \mathrm{~min}$ (extraction time starts with the presence of the first drop of condensate).

As shown in Figure 2, the lowest essential oil content was obtained at $900 \mathrm{~g}$ of sample weight and reached a maximum yield at $300 \mathrm{~g}$ and $500 \mathrm{~g}$ of sample weight. After $100 \mathrm{~min}$, when reducing the sample weight from $900 \mathrm{~g}$ to $300 \mathrm{~g}$, the essential oil content improved from $5.02 \pm 0.51 \%$ to the highest level of $6.21 \pm 0.34 \%$. Similarly, the content of essential oil obtained at $700 \mathrm{~g}$ of sample weight was only $5.45 \pm 0.45 \%$ compared to lower sample weights. Indeed, the increased volume of input resulted in a decrease in the essential oil content. This trend was due to the increased inlet volume, resulting in denser material density and lower vapor pressure of the water generated from the heater, making it difficult to carry out the release of essential oils from the feedstock of steam [21]. It is noteworthy that the overuse of raw materials leads to a longer extraction time, which is not economically favorable, to achieve the optimum yield. Apparently, with a sample mass of $300 \mathrm{~g}$ and $500 \mathrm{~g}$, the essential oil was saturated in $90 \mathrm{~min}$, whereas it takes a minimum of $100 \mathrm{~min}$ at a sample mass of $900 \mathrm{~g}$ to reach saturation and actual extraction time took an additional $20 \mathrm{~min}$ at the appearance of the first drop of condensate compared to smaller mass. The $300 \mathrm{~g}$ and $500 \mathrm{~g}$ sample weight obtained almost the same efficiency $(6.21 \pm 0.34 \%$ and $6.17 \pm 0.10 \%$ ) without adversely affecting the whole extraction process, so the $500 \mathrm{~g}$ input weight was chosen for the next experiments. 


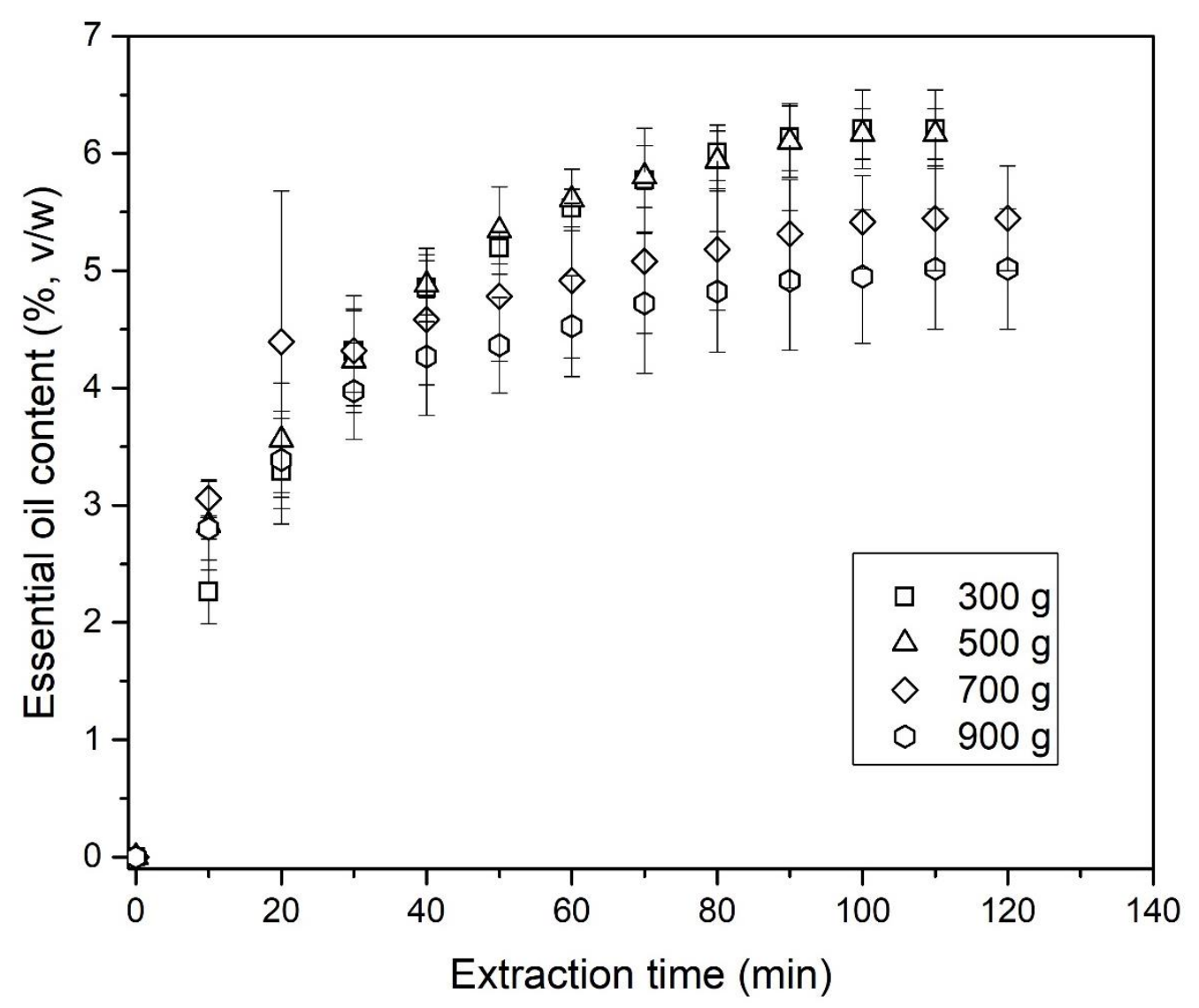

Figure 2. Effect of input sample weight over time in steam distillation.

Another important parameter that affects steam distillation is the steam flow rate. The rate of distillation depends on the amount of heat supplied to the system which ensures the beyond of boiling point of the steam and essential oil mixture. Steam flow rates $(1.8,2.1,2.4$, $3.4 \mathrm{~mL} / \mathrm{min}$ ) were obtained from the conversion parameter of the amount of heat supplied to the system, which corresponds to $120,130,140,150{ }^{\circ} \mathrm{C}$ from the heating system. The design ranges reported in each experiment ensure sufficient heat to evaporate the water without affecting the quality of the essential oil as well as being within the operating range of pilot-scale.

Figure 3 illustrates the amount of essential oil obtained at different extraction times and distillation rates. It was shown that increasing the steam flow rate from $1.8 \mathrm{~mL} / \mathrm{min}$ to $3.4 \mathrm{~mL} / \mathrm{min}$ improved the essential oil yield. The highest essential oil content $(6.37 \pm$ $0.30 \%, v / w$ ) was obtained when the distillation rate was set at $2.1 \mathrm{~mL} / \mathrm{min}$ for $100 \mathrm{~min}$. This suggest higher temperature input led to more energy dissipated into the plant materials. This effect improves the system's ability to distill pomelo essential oil from the surfaces of plants, as well as freeing the oil from untapped oil reservoirs and forcing it to diffuse through the plant particles. This in turn causes the initial increase in oil distillation rate and final essential oil yield. Moreover, the degradation of thermally unstable components can also occur during prolonged heating, reducing the yield of pomelo peel essential oil at lower steam flow rate $[11,20]$. 


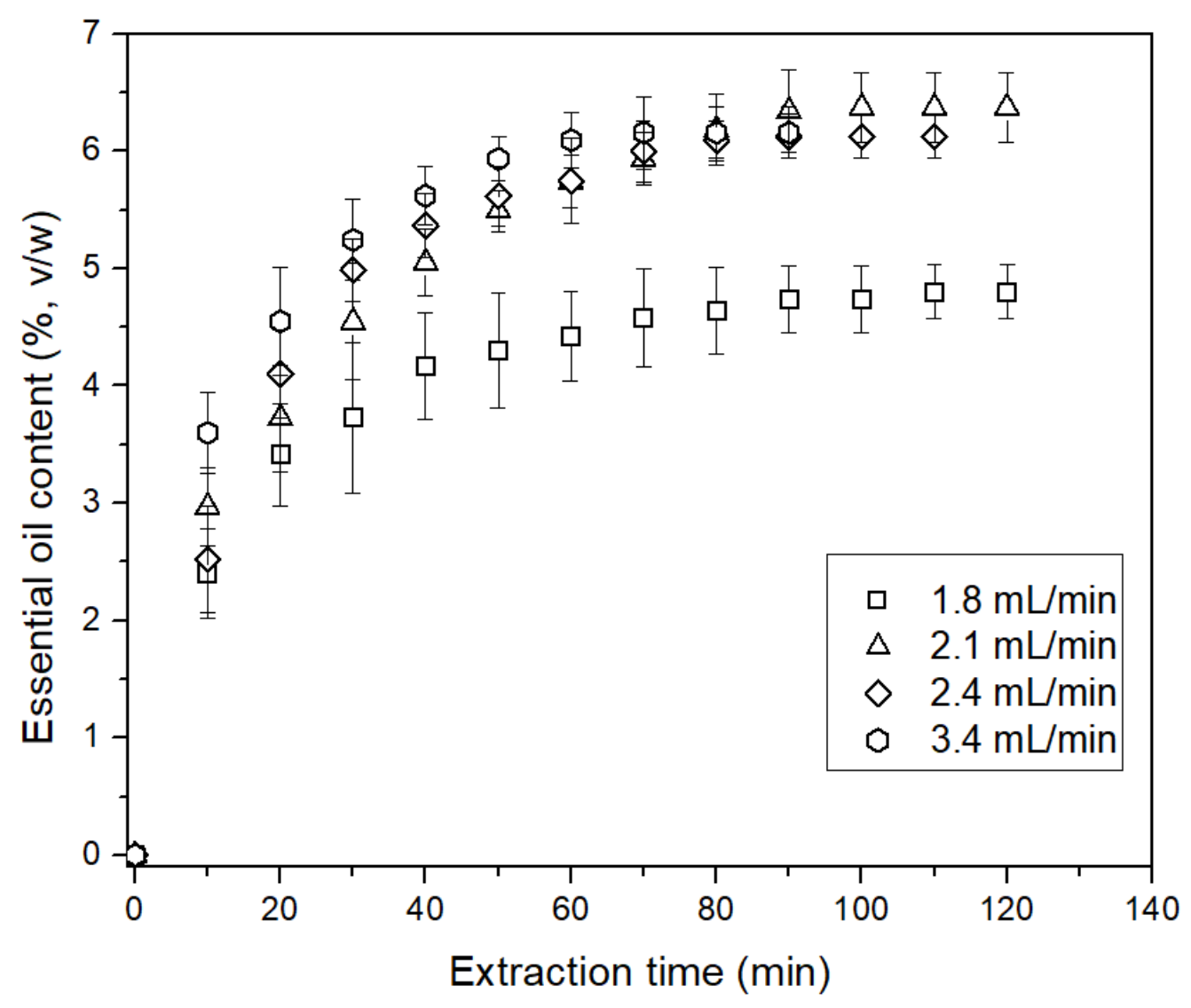

Figure 3. Effect of steam flow rate over time in steam distillation.

The yield obtained at high distillation rates $(6.13 \pm 0.08 \%$ and $6.16 \pm 0.10 \%$ at two operating conditions $2.4 \mathrm{~mL} / \mathrm{min}$ and $3.4 \mathrm{~mL} / \mathrm{min}$ ) showed lower values than the essential oil content at $2.1 \mathrm{~mL} / \mathrm{min}$. On the other hand, the rate at the lower limit of $1.8 \mathrm{~mL} / \mathrm{min}$, had the lowest efficiency $(4.8 \pm 0.23 \%)$ compared to those at the higher rate of 2.1-3.4 $\mathrm{mL} / \mathrm{min}$. This was explained by the insufficient dissipation of energy required to release the essential oil and the degradation of non-heat-resistant components when exposed to large amounts of heat. In this study, a distillation rate of $2.1 \mathrm{~mL} / \mathrm{min}$ was selected for further studies.

Extraction time is another factor that justifies the economic feasibility of the process. The extraction time should be long enough to extract all essential oils from the raw material. Extraction time varies depending on various factors such as extraction equipment and plant material sample. To find out the appropriate extraction time to extract pomelo peel essential oil, the yield of essential oil was screened and measured from the beginning of steam distillation until the amount of essential oil becomes constant. From Figures 2 and 3 , it can be seen that the extraction efficiency obtained at their respective optimal conditions reached its peak after $100 \mathrm{~min}$ from the first drop of condensate. This is consistent with previous results that most Citrus essential oils were exhaustively extracted after $60 \mathrm{~min}$ from the first drop of condensate [22,23]. In some cases, an extraction time of at least $120 \mathrm{~min}$ is required to observe the first drop of condensate. Therefore, under optimal conditions (material mass $500 \mathrm{~g}$ and distillation rate of $2.1 \mathrm{~mL} / \mathrm{min}$ ), $90 \mathrm{~min}$ was chosen as the optimal extraction time.

\subsection{Optimization of Essential Oils Extraction with RSM \\ 3.2.1. Suitability of the Model}

To optimize the distillation conditions, preliminary experiments were considered based on three factors, including mass of material $(\mathrm{g})$, steam flow rate $(\mathrm{mL} / \mathrm{min})$, and distillation time (min). Next, the RSM method was applied to optimize the conditions 
affecting the distillation of essential oils from pomelo peel. Based on the CCD, the quadratic model representing the relationship between the three factors was designed with five levels, as shown in Table 2.

Table 2. Survey value levels of three extracted factors in the model.

\begin{tabular}{cccccc}
\hline \multirow{2}{*}{ Code } & \multicolumn{5}{c}{ Levels } \\
\cline { 2 - 6 } & $-\boldsymbol{\alpha}$ & $\mathbf{- 1}$ & $\mathbf{0}$ & $\mathbf{+ 1}$ & $+\boldsymbol{\alpha}$ \\
\hline $\mathrm{A}$ & 163 & 300 & 500 & 700 & 836 \\
$\mathrm{~B}$ & 1.60 & 1.80 & 2.10 & 2.40 & 2.60 \\
$\mathrm{C}$ & 40 & 60 & 90 & 120 & 140 \\
\hline
\end{tabular}

The yield of essential oils is strongly dependent on the three factors. The experimental results of 20 experiments and the predictions of Design Expert 11 software are shown in Table 3. The values in Table 3 show that the experimental values do not deviate from the predicted values. Moreover, it can be seen that the concentration of essential oil obtained in experiment 17 was the highest $(6.28 \mathrm{~mL} / 100 \mathrm{~g})$ with the sample weight of $500 \mathrm{~g}$, steam flow rate of $2.1 \mathrm{~mL} / \mathrm{min}$, and extraction time $90 \mathrm{~min}$.

Table 3. Matrix of experimental and predicted values of 20 RSM experiments.

\begin{tabular}{|c|c|c|c|c|c|c|}
\hline \multirow[b]{2}{*}{ No. } & \multirow[b]{2}{*}{ Run } & \multicolumn{3}{|c|}{ Code } & \multicolumn{2}{|c|}{ Yield $(\%, \mathrm{~mL} / 100 \mathrm{~g})$} \\
\hline & & $\begin{array}{l}\text { A: Mass } \\
\text { (g) }\end{array}$ & $\begin{array}{l}\text { B: Steam Flow Rate } \\
(\mathrm{mL} / \mathrm{min})\end{array}$ & $\begin{array}{l}\text { C: Extraction Time } \\
\text { (min) }\end{array}$ & Actual & Residual \\
\hline 1 & 3 & 300 & 1.80 & 60 & 4.9640 & 0.1567 \\
\hline 2 & 14 & 700 & 1.80 & 60 & 4.5669 & 0.0302 \\
\hline 3 & 13 & 300 & 2.40 & 60 & 5.1625 & 0.0386 \\
\hline 4 & 8 & 700 & 2.40 & 60 & 4.9640 & -0.0181 \\
\hline 5 & 6 & 300 & 1.80 & 120 & 5.2784 & -0.0645 \\
\hline 6 & 10 & 700 & 1.80 & 120 & 4.6539 & 0.0571 \\
\hline 7 & 20 & 300 & 2.40 & 120 & 5.6530 & -0.0765 \\
\hline 8 & 16 & 700 & 2.40 & 120 & 5.6235 & 0.0006 \\
\hline 9 & 5 & 163 & 2.10 & 90 & 5.9062 & -0.0645 \\
\hline 10 & 7 & 836 & 2.10 & 90 & 5.0829 & -0.0252 \\
\hline 11 & 12 & 500 & 1.60 & 90 & 4.1334 & -0.1422 \\
\hline 12 & 19 & 500 & 2.60 & 90 & 4.8595 & 0.1308 \\
\hline 13 & 15 & 500 & 2.10 & 40 & 5.2734 & 0.0960 \\
\hline 14 & 4 & 500 & 2.10 & 140 & 5.8649 & -0.1135 \\
\hline 15 & 17 & 500 & 2.10 & 90 & 6.2500 & 0.0996 \\
\hline 16 & 11 & 500 & 2.10 & 90 & 6.0546 & -0.0054 \\
\hline 17 & 2 & 500 & 2.10 & 90 & 6.2757 & -0.0748 \\
\hline 18 & 1 & 500 & 2.10 & 90 & 5.9770 & 0.0077 \\
\hline 19 & 18 & 500 & 2.10 & 90 & 5.9770 & -0.0138 \\
\hline 20 & 9 & 500 & 2.10 & 90 & 6.1761 & -0.1422 \\
\hline
\end{tabular}

To elucidate the parameters of the operating parameters, the analysis of variance (ANOVA) is used. Table 4 presents a series of terms such as F-value, $p$-value, lack of fit, coefficient of determination, and adequate precision to assess the fit of the quadratic model. 
Table 4. ANOVA for Quadratic model.

\begin{tabular}{|c|c|c|c|c|c|c|}
\hline & Sum of Squares & df & Mean Square & F-Value & $p$-Value & \\
\hline Model & 7.32 & 9 & 0.8137 & 58.09 & $<0.0001$ & \multirow[t]{11}{*}{ significant } \\
\hline A & 0.5081 & 1 & 0.5081 & 36.27 & 0.0001 & \\
\hline B & 0.7317 & 1 & 0.7317 & 52.23 & $<0.0001$ & \\
\hline $\mathrm{C}$ & 0.4748 & 1 & 0.4748 & 33.89 & 0.0002 & \\
\hline $\mathrm{AB}$ & 0.0787 & 1 & 0.0787 & 5.62 & 0.0392 & \\
\hline $\mathrm{AC}$ & 0.0004 & 1 & 0.0004 & 0.0304 & 0.8652 & \\
\hline $\mathrm{BC}$ & 0.0700 & 1 & 0.0700 & 5.00 & 0.0494 & \\
\hline $\mathrm{A}^{2}$ & 0.7308 & 1 & 0.7308 & 52.17 & $<0.0001$ & \\
\hline $\mathrm{B}^{2}$ & 4.82 & 1 & 4.82 & 343.78 & $<0.0001$ & \\
\hline$C^{2}$ & 0.5696 & 1 & 0.5696 & 40.66 & $<0.0001$ & \\
\hline Residual & 0.1401 & 10 & 0.0140 & \multirow{4}{*}{0.5652} & & \\
\hline Lack of Fit & 0.0506 & 5 & 0.0101 & & 0.7268 & \multirow{4}{*}{$\begin{array}{c}\text { not } \\
\text { significant }\end{array}$} \\
\hline Pure Error & 0.0895 & 5 & 0.0179 & & & \\
\hline Cor Total & 7.46 & 19 & & & & \\
\hline$R^{2} 0.9812$ & Adjusted $R^{2} 0.9643$ & $\begin{array}{l}\text { Predicted } \\
\mathrm{R}^{2} 0.9271\end{array}$ & \multicolumn{2}{|c|}{$\begin{array}{c}\text { Adeq Precision } \\
24.1878\end{array}$} & & \\
\hline
\end{tabular}

Firstly, the F-value of the model is 58.09, showing that the RSM design model is statistically significant. In addition, $p$-value $<0.0001$ shows that the model shows only a $0.01 \%$ chance that the F-value can cause interference. Based on the F-values, the operating parameters are in the order steam flow rate (52.23) $>$ mass (36.27) $>$ extraction time (33.89). The $p$-value $<0.05$ indicates that the factors have statistically significant influences on the results of the model. In fact, if there are many values in the model with $p$-value $>0.1$, the reliability of the model is reduced. Therefore, it is necessary to remove values with $p$-value $>0.1$ when designing so that the statistical significance of the model is improved. On the above statistics table, we see that the factors $\mathrm{A}, \mathrm{B}, \mathrm{C}, \mathrm{AB}, \mathrm{BC}, \mathrm{A}^{2}, \mathrm{~B}^{2}, \mathrm{C}^{2}$ all have $p$-value < 0.05 , so they have a significant influence on the essential oil extraction performance when changing these factors.

The regression coefficient $\left(R^{2}\right)$ of 0.9812 showed that $98.12 \%$ of the experimental data are compatible with the predicted data by the model. In particular, the predicted $R^{2}(0.9643)$ is very close to adjusted $R^{2}(0.9891)$, suggesting a better fit for the quadratic model $[24,25]$.

In addition, the RSM model has an appropriate accuracy with adequate precision $(\mathrm{AP})=24.1878$ which is used to orient the design space. If it is greater than 4.0, this model can be used [25]. To sum up, this model could be suitable to predict the experimental data.

\subsubsection{Process Optimization}

The relationship between essential oil content $(\mathrm{Y})$ and independent variables $\mathrm{A}, \mathrm{B}$, and $C$ from Design-Expert 11 software is shown in the equation (Final Equation in Terms of Coded Factors) as follows:

$$
\mathrm{Y}=+6.12-0.1929 \mathrm{~A}+0.2315 \mathrm{~B}+0.1865 \mathrm{C}+0.0992 \mathrm{AB}-0.0073 \mathrm{AC}+0.0936 \mathrm{BC}-0.2252 \mathrm{~A}^{2}-0.5781 \mathrm{~B}^{2}-0.1988 \mathrm{C}^{2}
$$

where $\mathrm{A}$ is the mass of material $(\mathrm{g}), \mathrm{B}$ is the extraction rate $(\mathrm{mL} / \mathrm{min})$, and $\mathrm{C}$ is the extraction time (min).

According to Equation (8), the proposed quadratic mathematical model based on coded variables of extraction efficiency shows that the survey factor and essential oil yield, when the influence is positive, have a positive effect, and vice versa. From Equation (8), we have the factors including extraction rate $(\mathrm{B})$, time $(\mathrm{C})$, mass-temperature $(\mathrm{AB})$, and extraction rate-time $(\mathrm{BC})$, which are positively correlated with the yield of essential oils. When increasing the value of the above four survey factors, the yield of essential oils increases. At the same time, when increasing the value of factors such as ratio (A), AC factors, mass squared $\left(\mathrm{A}^{2}\right)$, temperature squared $\left(\mathrm{B}^{2}\right)$ and time squared $\left(\mathrm{C}^{2}\right)$, the essential 
oil yield tends to decrease due to negative correlation. Specifically, the range of influence values of the factors is depicted in Figure 4.

Design-Expert ${ }^{\circledR}$ Software

Factor Coding: Actual

Yield (\%)

4.13335

6.27574

$\mathrm{X} 1=\mathrm{A}:$ Mass

$\mathrm{X} 2$ = B: Steam flow rate

\section{Actual Factor}

C: Extraction time $=90$

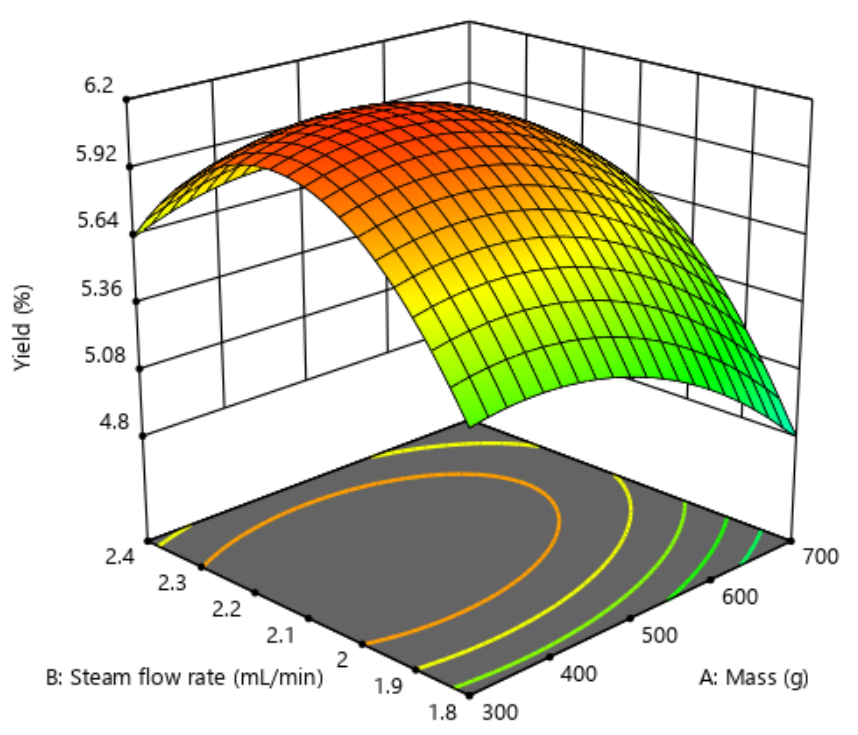

(a)

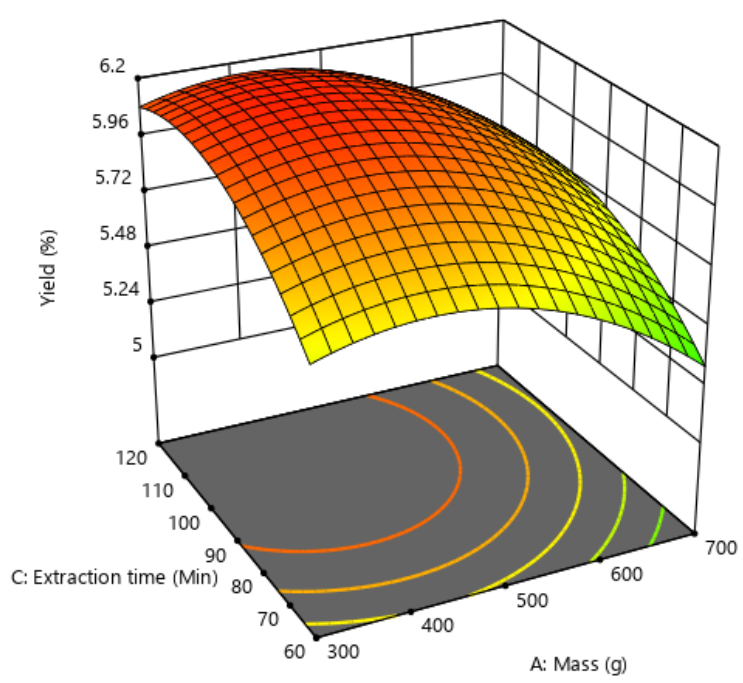

(b)
Design-Expert ${ }^{\circledR}$ Software Factor Coding: Actual

Yield (\%)

4.13335

$\mathrm{X} 1=\mathrm{A}:$ Mass

$\mathrm{X} 2=\mathrm{C}:$ Extraction time

Actual Factor

B: Steam flow rate $=2.1$ 


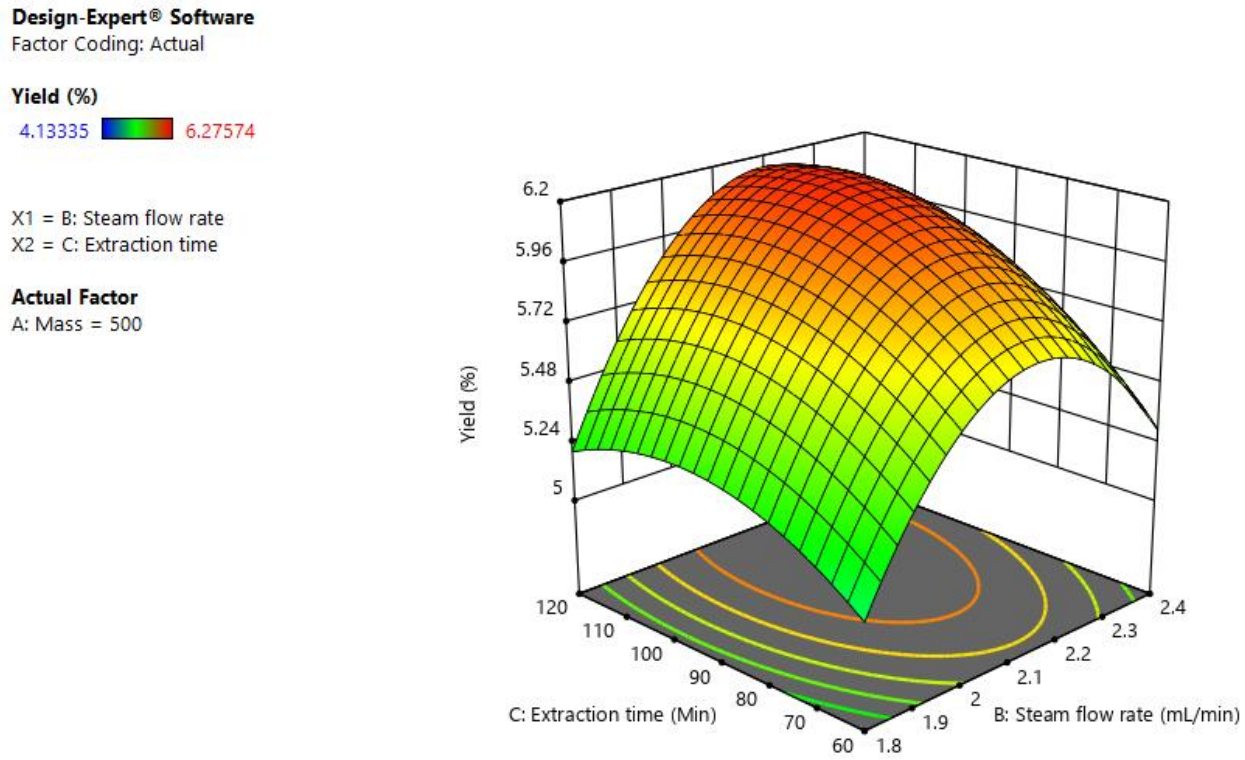

(c)

Figure 4. 3D diagram showing the effect of $(\mathbf{a}): \mathrm{AB},(\mathbf{b})$ : $(\mathrm{AC}),(\mathbf{c})$ : $\mathrm{BC}$ on the yield of essential oil.

The influence of factors on the yield of essential oils is depicted by three-dimensional surface response plots, as shown in Figure 4. The red area of the graph represents the highest essential oil yield, whereas the blue area describes a lower result. The green to red color scale reveals the essential oil content values from 4.1334 to $6.2757 \%$.

Figure $4 \mathrm{a}$ shows the interaction between mass and steam flow rate on essential oil content. Based on the variation of the color scale in the chart, the yield of essential oils changes when the values of these two factors vary. We first considered the influence of steam flow on the extraction efficiency of essential oils. At $2.1 \mathrm{~mL} / \mathrm{min}$, the obtained essential oil content tended to remain the same when increasing the input of sample weigh to the extraction system; however, the essential oil content showed a downward trend with the sample loading from $580 \mathrm{~g}$ to $700 \mathrm{~g}$. In fact, this can be easily observed in Equation (8), which showed a negative correlation of this factor with essential oils yield. In terms of steam flow rate variation, it experienced the same trend as the sample loading factor. Increasing the flow rate from $1.8 \mathrm{~mL} / \mathrm{min}$ to $2.3 \mathrm{~mL} / \mathrm{min}$ led to an increase in the amount of essential oil, but there was a downward trend when increasing to $2.4 \mathrm{~mL} / \mathrm{min}$. This was ascribed to the degradation of essential oils when exposed to to high temperatures for long periods of time [26,27]. In general, the interaction of mass and steam flow rate had the same correlation in which the essential oil yield increased to the highest value at optimal values of these factors and started reducing when exceeding the threshold of these factors. The essential oil content reached the highest $(5.8 \%)$ at the rate of 2.1 to $2.3 \mathrm{~mL} / \mathrm{min}$ and at the sample weight from $300 \mathrm{~g}$ to $580 \mathrm{~g}$.

Figure $4 \mathrm{~b}$ hows the interaction between the two factors of material weight and extraction time. At the extraction time of $90 \mathrm{~min}$, the yield gradually decreased when the sample weight increased from $300 \mathrm{~g}$ to $700 \mathrm{~g}$, which was consistent with our single-factor survey. The essential oil content tended to increase when increasing the extraction time. At the input value of $300 \mathrm{~g}$ to $600 \mathrm{~g}$, the highest yield of essential oil was obtained after $80 \mathrm{~min}$ of extraction. From Figure $4 b$, it can be observed that the histogram decreased in color scale and had a slope from the upper limit of extraction time and mass. This showed the negative correlation of these two factors. Specifically, the essential oil content tended to decrease with the excess of sample loading ( $>600 \mathrm{~g}$ ), as shown by the green spaces in the color scale. The highest yield of essential oils was obtained when a low loading of sample was subjected to the system associated with an extended extraction time. However, both factors maintained the highest 
color scale at the central values, which was almost unaffected by this negative correlation. The obtained essential oil content was relatively high (6\%), with the sample loading of 300 to $600 \mathrm{~g}$ and the extraction time of more than $80 \mathrm{~min}$.

Finally, Figure $4 \mathrm{c}$ shows the interaction between steam flow rate and extraction time. The maximum value $(6 \%)$ lies near the central value, when the steam flow rate ranged from approximately $2.05 \mathrm{~mL} / \mathrm{min}$ to $2.30 \mathrm{~mL} / \mathrm{min}$ at intervals of 80 to $120 \mathrm{~min}$. As observed from the chart, the essential oil yield increased from $1.80 \mathrm{~mL} / \mathrm{min}$ to $2.30 \mathrm{~mL} / \mathrm{min}$ and showed a decrease when exceeding the threshold of $2.40 \mathrm{~mL} / \mathrm{min}$. These parameters presented a curve that went from green to red and a downward trend which was depicted by a gradual change in color to orange. In general, the interaction of these two factors was positively correlated. It can be seen that the interaction of steam flow rate and extraction time had the greatest influence on the extraction of pomelo essential oil by steam distillation.

\subsubsection{Verification of Optimal Condition}

Based on the analyzed data, Figure 5 shows the binding between variables in model verification. This is aimed at optimizing the extraction of pomelo peel essential oil by steam distillation. Accordingly, the most desirable solution is listed in Figure 5. Desirability was $97.9 \%$, showing a great possibility of accomplishing the goal. The model's optimization conditions were $422 \mathrm{~g}$ of loading sample with a steam flow rate of $2.2 \mathrm{~mL} / \mathrm{min}$ for $106 \mathrm{~min}$ which resulted in the essential oils yield of $6.30 \%$, close to the predicted result of $6.23 \%$. This result confirmed the good compatibility with the proposed model and showed the potential in practical implications. Previous studies $[18,28]$ also mentioned that the extraction of pomelo essential oil was carried out for more than $100 \mathrm{~min}$ to obtain the maximum efficiency for both microwave extraction and hydrodistillation extraction methods. Dao et al. [16] attempted the extraction of pomelo essential oil by the hydrodistillation method. The yield was $1.9 \%$ (equivalent to $6.3 \%$ when converted to dry weight) at the extraction temperature of $120{ }^{\circ} \mathrm{C}$, the ratio of $5: 1 \mathrm{~mL} / \mathrm{g}$ for $105 \mathrm{~min}$. The process performance is almost similar to this study. Another study regarding optimization of pomelo essential oil extraction by microwave-assisted hydro-distillation was reported by Hien et al. [28]. RSM was used for optimization with optimal efficiency of $4.5 \%$, corresponding to a power of $403.115 \mathrm{~W}$, a ratio of $3.119 \mathrm{~mL} / \mathrm{g}$ of fresh material, and a rather long extraction time $(117.336 \mathrm{~min})$. Although the process efficiency is relatively high, in contrast, the extraction process uses a lot of energy and is difficult to scale up production which is a goal of this research.
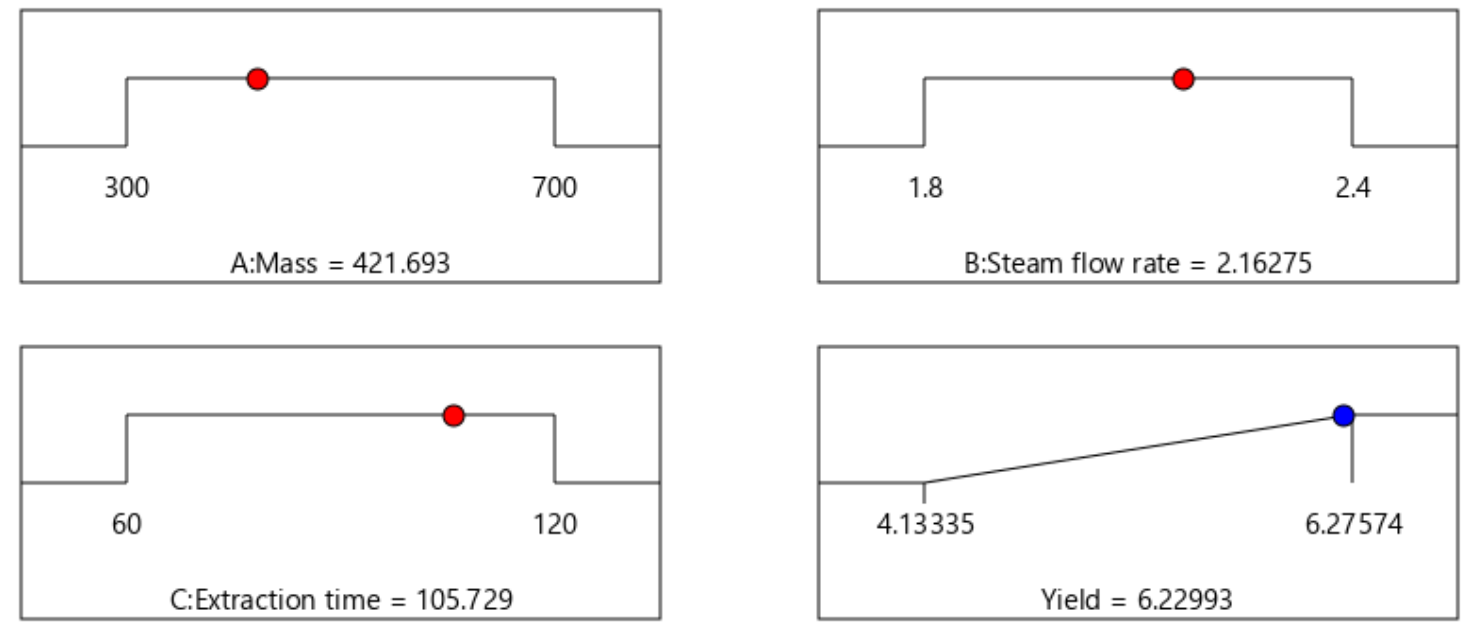

Figure 5. Optimal conditions obtained from RSM.

Where, the red point is the value of the influencing variables and the blue point is the value of the objective function which is the optimal condition of the extraction process. 


\subsection{Kinetic Model Study}

The extraction kinetics were evaluated by observing essential oils yield over time. The experimental data were fitted with four first-order kinetic models including model 1 (Equation (2)), model 2 (Equation (3)), model 3 (Equation (4)), and model 4 (Equation (5)). Nonlinear forms of the equations at different steam flow rates $(1.8-3.4 \mathrm{~mL} / \mathrm{min})$ were used to verify the kinetic models and proposed essential oil extraction mechanism (Figure 6A-D).

As shown in Figure 6, it can be seen that the experimental data points are distributed on the curve, implying that the equations of the kinetic models were suitable to describe the experimental data. The experimental kinetic curves showed the typical extraction performance, which mainly comprised of two stages: (1) rapid extraction (washing phase), in which the essential oils were located on the outer surface of the washed material and (2) slow extraction stage (diffusion stage), in which the essential oils localized inside raw materials moved to the external environment. The second stage is characterized by a slow process, showing the gradual improvement of essential oil yield [11,20]. The curves, showing the variations of pomelo peel essential oil yield, were sigmoid or S-shaped with upward curvature. This was consistent with previous experimental data (Figures 2 and 3), showing that the yield of essential oils increased rapidly in the early stage (i.e., the fast distillation phase) and experienced a slower rate in later stage until reaching a constant rate (i.e., slow distillation phase).

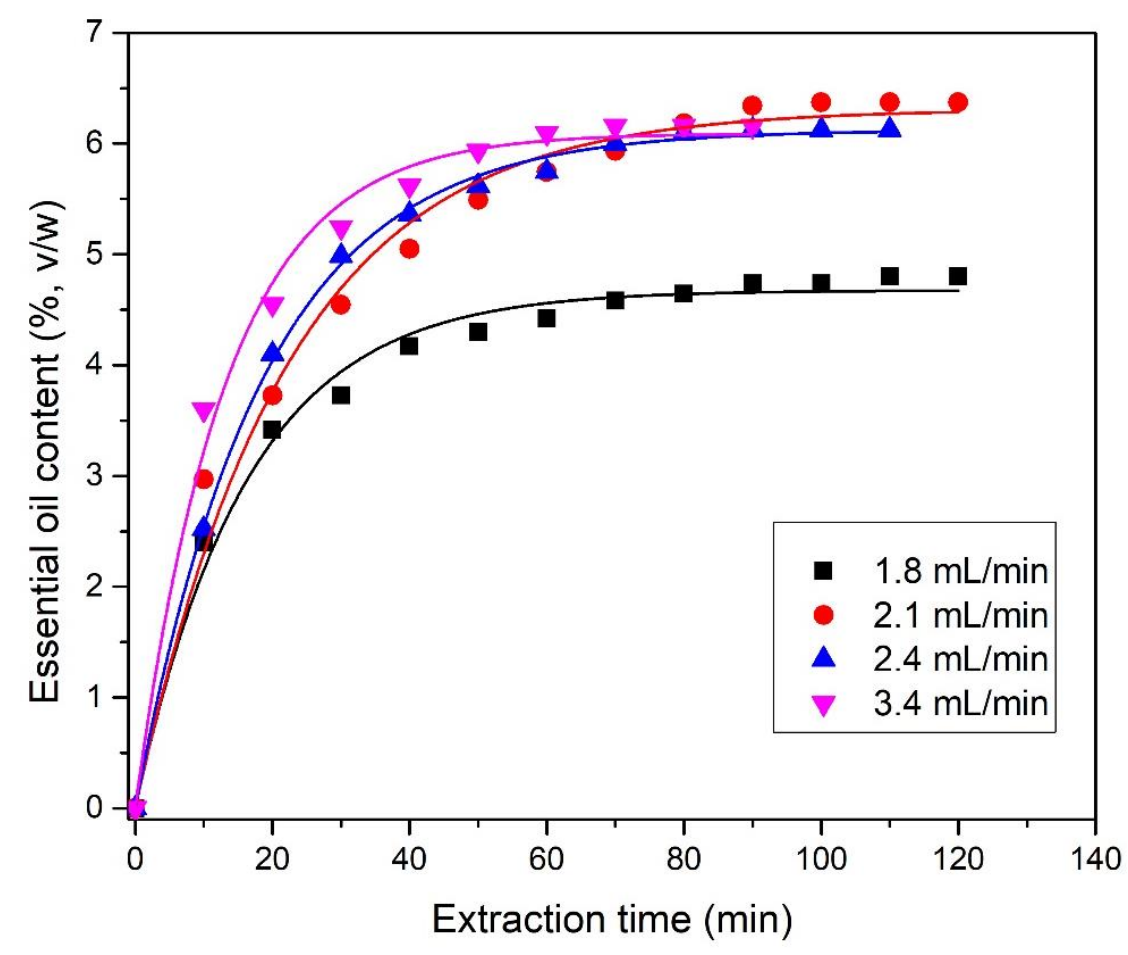

(A)

Figure 6. Cont. 


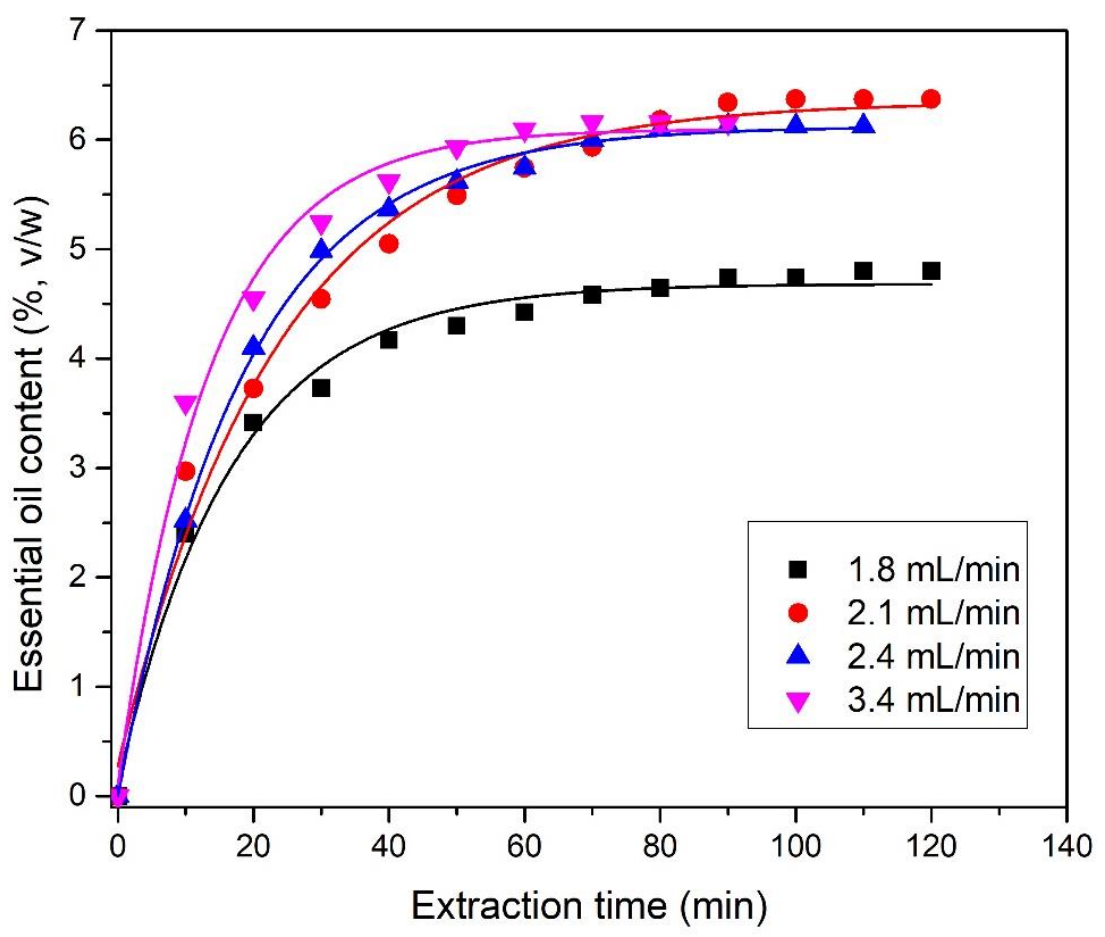

(B)

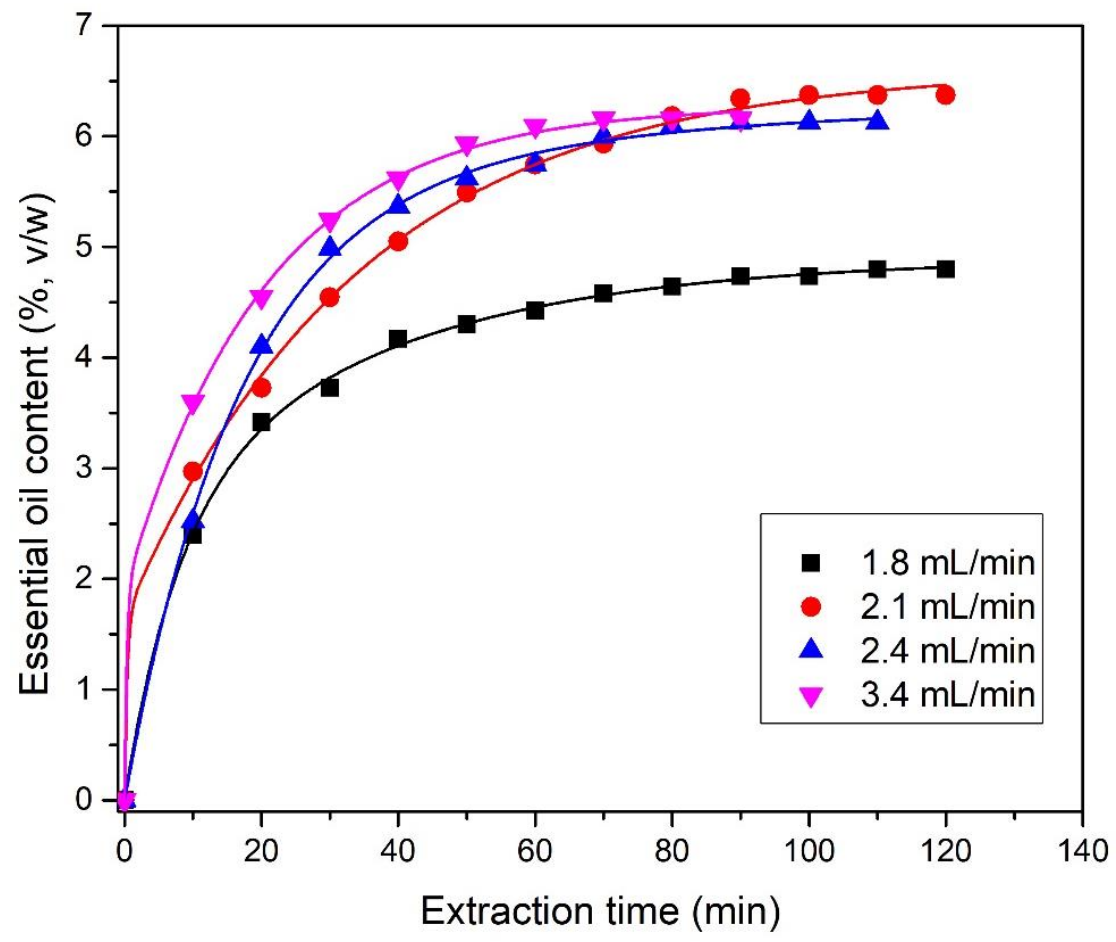

(C)

Figure 6. Cont. 


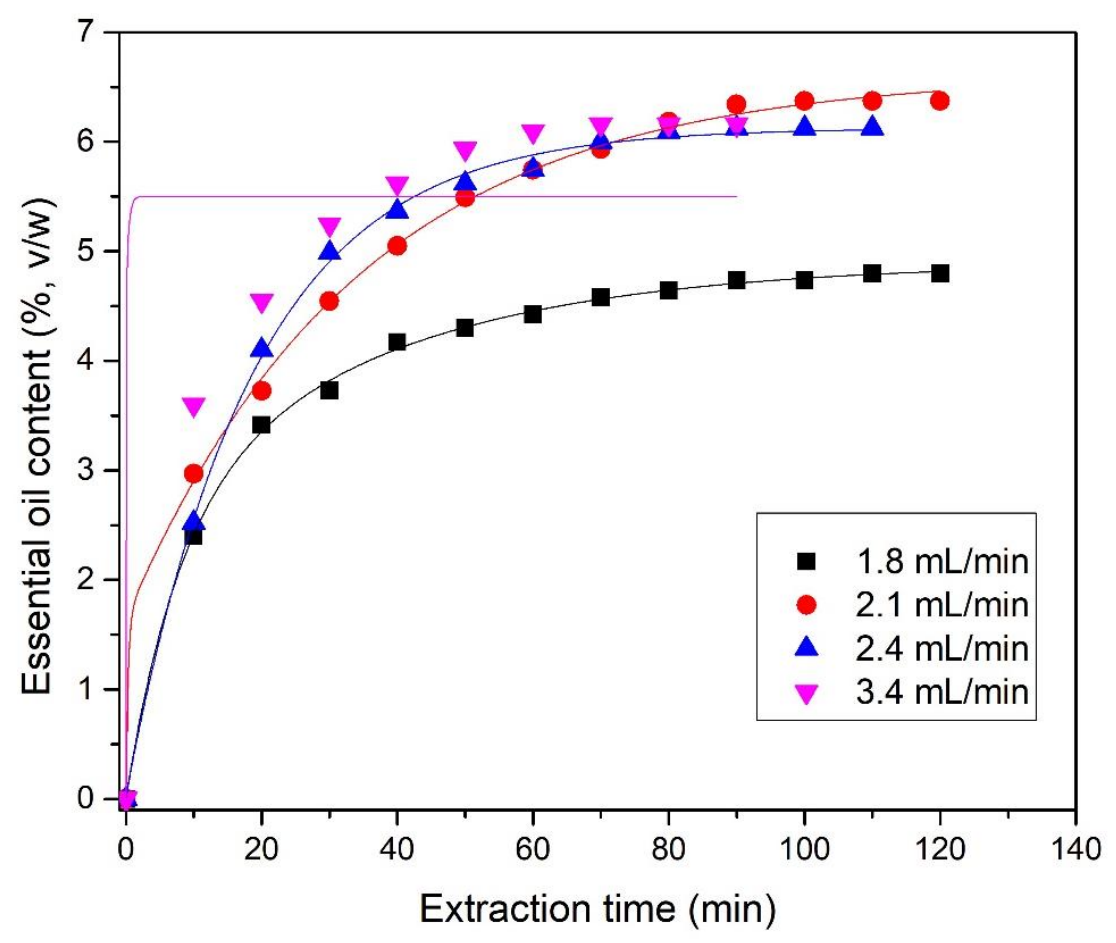

(D)

Figure 6. Kinetic model of steam distillation at different steam flow rates with (A): model 1; (B): model 2; (C): model 3; (D): model 4.

According to Figure 6, three kinetic steps could be observed. First, a nearly linear increase in essential oils yield occurred at $0-10 \mathrm{~min}$ (phase 1 , followed by a rapid increase in extraction yield at 10-50 min (phase 2), followed by a slow increase with an extended extraction time, until a constant yield was reached after $130 \mathrm{~min}$. In this case, more than $90 \%$ of the recovered oil was extracted in the second stage (at optimal steam flow rate of $2.1 \mathrm{~mL} / \mathrm{min}$ ). The sigmoid curve was also observed in previous studies regarding the kinetics of the distillation of rosemary [29] and Artisica judaica L. essential oil [30]. Furthermore, it was reported that essential oil also followed three different phases: the equilibrium phase, the intermediate transition phase, and the diffusion phase [31]. In particular, a decrease in the diffusion rate was observed with prolonged time due to the negligible amount of essential oils remaining in the plant tissue.

The kinetic parameters of the models include: the amount of oil in equilibrium $\left(q_{\infty}\right)$ and the essential oil fraction extracted through the washing step, with unhindered and hindered diffusion $\left(f_{\mathrm{w}}, \mathrm{f}_{\mathrm{d} 1}, \mathrm{f}_{\mathrm{d} 2}\right)$, respectively. The estimated parameters of all models are listed in Table 5. The coefficient $\mathrm{R}^{2}$ is a commonly used parameter to determine the relationship between experimental data and the model. In this study, all models under different extraction conditions achieved very high $R^{2}\left(R^{2}>0.95\right)$, except the one at $3.4 \mathrm{~mL} / \mathrm{min}$ in model 4 . These models can be considerably suitable for the kinetic characterization study. To select the most suitable model, the value \%q is also a considerable factor as it presents the percentage of deviation between the content of essential oil at saturation between the experimental values and predicted values from the model. From the results of $R^{2}$ and \%q values, model 3 showed better experimental data than others. This result was due to the higher coefficient of determination. $R^{2}$ and deviation of the actual and calculated essential oils were within the allowable range (less than $5 \%$ ) which was considered as a supporting factor in assessing the fit of the model [20]. More specifically, the coefficient $\mathrm{R}^{2}$ at the optimal position $(2.1 \mathrm{~mL} / \mathrm{min})$ of the model 3 was shown to obtain a high value (0.99576). 
Table 5. Kinetic parameters of pomelo peel essential oil extraction by steam distillation.

\begin{tabular}{|c|c|c|c|c|c|c|c|c|c|c|c|c|}
\hline No. & Model & $\begin{array}{c}\text { Rate } \\
\text { (mL/min) }\end{array}$ & $q_{\infty, \exp }$ & $q_{\infty, c a l}$ & $\mathbf{f}_{\mathbf{w}}$ & $\mathbf{f}_{\mathrm{d} 1}$ & $\mathbf{f}_{\mathrm{d} 2}$ & $\mathbf{k}_{\mathrm{w}}$ & $\begin{array}{c}\mathrm{kd}_{1} \\
\left(\min ^{-1}\right)\end{array}$ & $\begin{array}{c}\mathrm{kd}_{2} \\
\left(\min ^{-1}\right)\end{array}$ & $\mathbf{R}^{2}$ & $\% q$ \\
\hline \multirow{4}{*}{1} & \multirow{4}{*}{$\begin{array}{l}\text { Simple } \\
\text { diffusion } \\
\text { without } \\
\text { washing }\end{array}$} & 1.8 & 4.80 & 4.68 & - & - & - & - & 0.0617 & - & 0.98932 & 2.50 \\
\hline & & 2.1 & 6.37 & 6.31 & - & - & - & - & 0.0454 & - & 0.9831 & 0.94 \\
\hline & & 2.4 & 6.13 & 6.12 & - & - & - & - & 0.0539 & - & 0.9987 & 0.16 \\
\hline & & 3.4 & 6.16 & 6.09 & - & - & - & - & 0.0754 & - & 0.9907 & 1.14 \\
\hline \multirow{4}{*}{2} & \multirow{4}{*}{$\begin{array}{l}\text { Instantaneous } \\
\text { washing } \\
\text { followed by } \\
\text { diffusion }\end{array}$} & 1.8 & 4.80 & 4.68 & 0.0223 & & & & 0.0600 & - & 0.98886 & 2.5 \\
\hline & & 2.1 & 6.37 & 6.35 & 0.0437 & - & - & - & 0.0426 & - & 0.98383 & 0.31 \\
\hline & & 2.4 & 6.13 & 6.12 & $5.51 \times 10^{-4}$ & - & - & - & 0.0539 & - & 0.99855 & 0.16 \\
\hline & & 2.7 & 6.16 & 6.10 & 0.0169 & - & - & - & 0.0739 & - & 0.98979 & 0.97 \\
\hline \multirow{4}{*}{3} & \multirow{4}{*}{$\begin{array}{l}\text { Simultaneous } \\
\text { washing and } \\
\text { unhindered } \\
\text { diffusion }\end{array}$} & 1.8 & 4.80 & 4.90 & 0.3880 & - & - & 0.0281 & 0.1308 & - & 0.99884 & 2.08 \\
\hline & & 2.1 & 6.37 & 6.76 & 0.3412 & - & - & 0.1515 & 0.0236 & - & 0.99576 & 3.92 \\
\hline & & 2.4 & 6.13 & 6.38 & 0.8884 & - & - & 0.0589 & 0.0112 & - & 0.99876 & 4.08 \\
\hline & & 3.4 & 6.16 & 6.29 & 0.3023 & - & - & 3.0759 & 0.0482 & - & 0.99928 & 2.11 \\
\hline \multirow{4}{*}{4} & \multirow{4}{*}{$\begin{array}{l}\text { Simultaneous } \\
\text { washing, } \\
\text { unhindered } \\
\text { diffusion and } \\
\text { hindered } \\
\text { diffusion }\end{array}$} & 1.8 & 4.80 & 4.90 & 0.4882 & 0.5122 & $1.95 \times 10^{-9}$ & 0.0281 & 0.1309 & 0.5609 & 0.99826 & 2.08 \\
\hline & & 2.1 & 6.37 & 6.62 & 0.7502 & 0.2498 & $9.33 \times 10^{-9}$ & 0.029 & 3.0357 & 0.0289 & 0.9980 & 3.93 \\
\hline & & 2.4 & 6.13 & 6.13 & 0.9938 & 0.0062 & $3.85 \times 10^{-9}$ & 0.0535 & 2.5181 & 0.1291 & 0.9974 & 0 \\
\hline & & 3.4 & 6.16 & 5.5 & & & & & & & 0.42677 & 10.71 \\
\hline
\end{tabular}

From Table 5, it can be observed that the kinetic parameters related to the extraction rate constant $\left(\mathrm{k}_{\mathrm{d} 1}\right)$ seemed to be reduced with an elevated distillation rate, whereas the rate constant of the washing process $\mathrm{k}_{\mathrm{w}}$ increased with the same trend as the rate of distillation at $1.8 \mathrm{~mL} / \mathrm{min}$ and $2.1 \mathrm{~mL} / \mathrm{min}$. However, the parameter at $2.4 \mathrm{~mL} / \mathrm{min}$ tended to decrease and it experienced dramatic increase at $3.4 \mathrm{~mL} / \mathrm{min}, 3.0759$ at $\mathrm{k}_{\mathrm{w}}$, and 0.0482 at $\mathrm{k}_{\mathrm{d} 1}$, respectively. This fluctuation could be explained by the mixing of assumed parameters from the models and the degradation of compounds in the essential oil when subjected to the heating process for a long time. The decline in the final stage when fitting the model was understood as the diffusion phase, which caused the variation of the kinetic parameters in the model regardless of the compatibility of $R^{2}$ and $\% q$ values to the experimental values.

At the distillation rate of $2.1 \mathrm{~mL} / \mathrm{min}$ in model 3 , a high $\mathrm{k}_{\mathrm{w}}$ value $(0.1515)$ was obtained, indicating that the steam flow rate is strongly related to the washing constant. This also implied that the steam flow rate had a greater influence on the washing phase than the diffusion phase in this model. Furthermore, the $\mathrm{f}_{\mathrm{w}}$ value of model 3 at the steam flow rate of $2.1 \mathrm{~mL} / \mathrm{min}$ obtained higher values than the others. This parameter suggested that the extraction conditions increased the availability of essential oils for washing by disrupting the cell wall. In general, at higher steam flows, the washing and diffusion of essential oils from the pomelo peel were faster and easier, and the extraction process progressed to more of the washing phase, with a corresponding decrease in the extraction phase diffusion. However, when the steam flow rate exceeded the threshold of $2.4 \mathrm{~mL} / \mathrm{min}$, the occurring reverse effect affected the kinetic parameters and significantly reduced the extraction efficiency. The results showed that the low extraction yield could be the result of over-heating, leading to undesirable solvent extraction, thermal degradation of heat sensitive substances, and instability of compounds [32,33].

Indeed, the simultaneous washing and unhindered diffusion model in the nonlinear form had a high $\mathrm{R}^{2}$ coefficient of 0.99576 and $\% \mathrm{q}$ of $3.92 \%$ at the location where the maximum essential oil content $(2.1 \mathrm{~mL} / \mathrm{min})$ was chosen as the suitable model, as well as the non-linear form of the model that can clearly describe the extraction kinetics. Previous studies made similar observations that the non-linear form was suitable for describing the kinetics of essential oil extraction and that the equation in the nonlinear form could produce fewer errors, leading to fewer violations of the theory of the model than the linear 
form $[34,35]$. With the above data, the nonlinear equation of the washing and diffusion model was not hindered and was found to be reasonable and reliable in interpreting the experimental data of the extraction process.

Based on the assumptions of model 3 with the combination of experimental data, conclusions can be made. First, the kinetics of pomelo peel extraction was described by the simultaneous unhindered washing and diffusion model. Second, the kinetic model of direct water extraction was characterized by two stages of washing and diffusion as the main process. Washing is considered as a rapid oil distillation process, referring to the stage where the essential oil is washed from the inside and outside of the raw material surface. This stage is characterized by a rapid increase in the quantity of the essential oil at the beginning of the distillation process. The next stage, which plays a major role in the extraction mechanism, is the diffusion stage, which depicts the slow distillation of the essential oils. During this phase, the essential oil is diffused from the inner parts of the pomelo peel towards the outer surfaces and then it is carried away by steam flows. Unobstructed diffusion involves mass transfer of essential oils from ruptured organs without any restrictions. The diffusion phase is characterized by a slow increase in the yield of the essential oils during distillation [36].

The kinetic model of pomelo essential oil extraction by steam distillation by simultaneous washing and unhindered diffusion at the optimal point (model $3,2.1 \mathrm{~mL} / \mathrm{min}$ ) is shown as follows:

$$
\frac{\mathrm{q}}{\mathrm{q}_{\infty}}=1-0.3412 \times \mathrm{e}^{-0.1515 \mathrm{t}}-(1-0.3412) \times \mathrm{e}^{-0.0236}
$$

where $\mathrm{q}$ is the amount of essential oil obtained in the material at time $\mathrm{t}(\mathrm{mL} / 100 \mathrm{~g})$, and $\mathrm{q}_{\infty}$ is the amount of essential oil obtained until saturation $(\mathrm{mL} / 100 \mathrm{~g})$.

\subsection{Activity Energy}

The Arrhenius equation is used to show the dependence of temperature and mass transfer coefficient as follows:

$$
K=A \cdot e^{-\frac{E_{a}}{R T}}
$$

where $k$ is the coefficient of mass transfer $\left(\mathrm{min}^{-1}\right), A$ the frequency factor $\left(\mathrm{min}^{-1}\right), E_{a}$ is the activation energy $\left(\mathrm{kJ} \cdot \mathrm{mol}^{-1}\right), R$ is the universal gas constant $\left(8.314 \times 10^{-3} \mathrm{~kJ} \cdot \mathrm{mol}^{-1} \cdot \mathrm{K}^{-1}\right)$, and $T$ is the absolute temperature $(\mathrm{K})$.

For each stage of the process, the Arrhenius plot (natural logarithm of mass transfer coefficient against reciprocal of absolute temperature) appeared linear where the logarithm of $\mathrm{k}$ decreased linearly with increasing $1 / \mathrm{T}$. The values of the Arrhenius equation parameters were obtained from the slope and intercept of each curve (Table 6). Low activation energy values were obtained at the unhindered diffusion stage and high values were obtained at the washing stage $\left(167.43 \mathrm{~kJ} \cdot \mathrm{mol}^{-1}\right)$. All these values were characteristics of an extraction process of a physical nature. The frequency value of the washing phase was approximately 1.5 times greater than that of the diffusion phase.

Table 6. Parameters of the Arrhenius equation.

\begin{tabular}{ccc}
\hline \multirow{2}{*}{ Parameters } & \multicolumn{2}{c}{ Step } \\
\cline { 2 - 3 } & Washing & Diffusion 1 \\
\hline $\mathrm{Ea}\left(\mathrm{kJ} \cdot \mathrm{mol}^{-1}\right)$ & 167.43 & 96.25 \\
$\mathrm{~A}\left(\mathrm{~min}^{-1}\right)$ & 47.79 & 31.91 \\
$\mathrm{R}^{2}$ & 0.5717 & 0.7154 \\
\hline
\end{tabular}

\subsection{Thermodynamic Analysis}

The extraction of essential oils uses the amount of heat supplied to the system; thus thermodynamic evaluation, which represents the energy exchange of the extraction process with the environment, should be taken into account. 
The thermodynamic parameters, which included differential enthalpy $\left(\Delta H^{\circ}\right)$, differential entropy $\left(\Delta S^{\circ}\right)$, and Gibbs free energy $\left(\Delta G^{\circ}\right)$ at various temperatures (393-423 $\mathrm{K}$ ) for the essential oil extraction process, were calculated from Van't Hoff equation:

$$
\ln \mathrm{K}=-\frac{\Delta H^{\circ}}{\mathrm{RT}}+\frac{\Delta S^{\circ}}{\mathrm{R}}
$$

where $\mathrm{R}$ is the universal gas constant $\left(8.314 \mathrm{~J} \cdot \mathrm{mol}^{-1} \cdot \mathrm{K}^{-1}\right), \mathrm{T}$ is the absolute temperature $(\mathrm{K})$, and $\mathrm{K}$ is the constant at equilibrium defined as [37]:

$$
K=\frac{\mathrm{q}_{\mathrm{T}}}{\mathrm{q}_{\infty}-\mathrm{q}_{\mathrm{T}}}
$$

where $\mathrm{q}_{\mathrm{T}}$ is the content of extracted essential oil that is saturated at temperature $\mathrm{T}(\mathrm{K})$, and $\mathrm{q}$ solid $\left(q_{\infty}-q_{T}\right)$ is the amount of essential oil that has not been extracted at temperature $\mathrm{T}(\mathrm{K})$, calculated from the difference in the amount of saturated essential oil at temperature $\mathrm{T}$ and the amount of initial essential oil in the materials.

After calculating the values of $\mathrm{K}$ for each evaluated condition, graphs were generated with the data $\ln \mathrm{K}$ versus $1 / \mathrm{T}$, and data were adjusted to linear regression models. The values were obtained from the slope of the lines, representing the quatities $\left(\Delta H^{\circ} / R\right)$ and intercept of the quantities $\left(\Delta S^{\circ} / R\right)$.

Gibbs free energy for the different temperatures was estimated by the equation (13):

$$
\Delta G^{\circ}=\Delta H^{\circ}-T \times \Delta S^{\circ}
$$

The thermodynamic parameters of pomelo essential oil extraction are shown in Table 7. $\Delta H^{\circ}, \Delta S^{\circ}$ values were found to give positive results over the extraction temperature range, which indicated both endothermic and irreversible properties of the essential oil extraction process. Previous studies on the oil extraction process from plants also showed that 14.27-28.247 J.mol ${ }^{-1}$. Santos et al. [37], in the study of Jatropha curcas L. oil extraction process, obtained the $\Delta H^{\circ}$ values of $14.27-18.60 \mathrm{~kJ} \mathrm{~mol}^{-1}$ and $\Delta S^{\circ}$ of $38.74-56.14 \mathrm{~J} . \mathrm{mol}-1 . \mathrm{K}^{-1}$ for different raw material sizes. Abed et al. [38] performed a thermodynamic evaluation of peppermint leaf oil extract; the obtained values of $\Delta H^{\circ}$ and $\Delta S^{\circ}$ were $28.247 \mathrm{~kJ} / \mathrm{mol}$ and $90.905 \mathrm{~kJ} / \mathrm{mol}$, respectively. The $\Delta H^{\circ}$ of $24.21 \mathrm{~kJ} \cdot \mathrm{mol}^{-1}$ and $\Delta S^{\circ}$ of $63.66 \mathrm{~J} . \mathrm{mol}-1 . \mathrm{K}^{-1}$ obtained during the pomelo essential oil extraction were acceptable. More specifically, the increase in entropy in the mixture was due to the migration from solid to liquid phase during extraction [39]. In addition, the $\Delta G^{\circ}$ obtained from Equation (13) gave negative values as well as showing that the reaction discharged spontaneously at the investigated temperatures (preferred with increasing temperature), and the reaction occurred in the forward direction. which has been not previously tested.

Table 7. Thermodynamic parameters of the extraction proces.

\begin{tabular}{cccccc}
\hline $\mathbf{T}(\mathbf{K})$ & $\mathbf{Q}$ (Liquid) (\%) & $\mathbf{Q}$ (Solid) (\%) & $\mathbf{H}\left(\mathbf{J} \times \mathbf{m o l}-{ }^{1}\right)$ & $\mathbf{S}\left(\mathbf{J} \times \mathbf{m o l}-{ }^{1} \cdot \mathbf{K}-{ }^{1}\right)$ & $\mathbf{G}^{\circ}\left(\mathbf{k J} \times \mathbf{m o l}-{ }^{1}\right)$ \\
\hline 393 & 4.8007 & 2.625 & & & -35.02 \\
403 & 6.373 & 1.0529 & -0.2469 & 89.1095 & -34.93 \\
413 & 6.125 & 1.301 & & & -35.02 \\
423 & 6.1574 & 1.1685 & & & -35.02 \\
\hline
\end{tabular}

\subsection{GC-MS Analysis}

Pomelo essential oil was extracted by steam distillation under optimal conditions including $422 \mathrm{~g}$ of loading sample and a steam flow rate of $2.16 \mathrm{~mL} / \mathrm{min}$ for $106 \mathrm{~min}$. The GC-MS analysis result in Figure 7 has identified six compounds in the pomelo peel essential oils and $100 \%$ of the components, which are mainly monoterpenes, have been identified. Chemical components of pomelo essential oil are also reported in Table 8. 


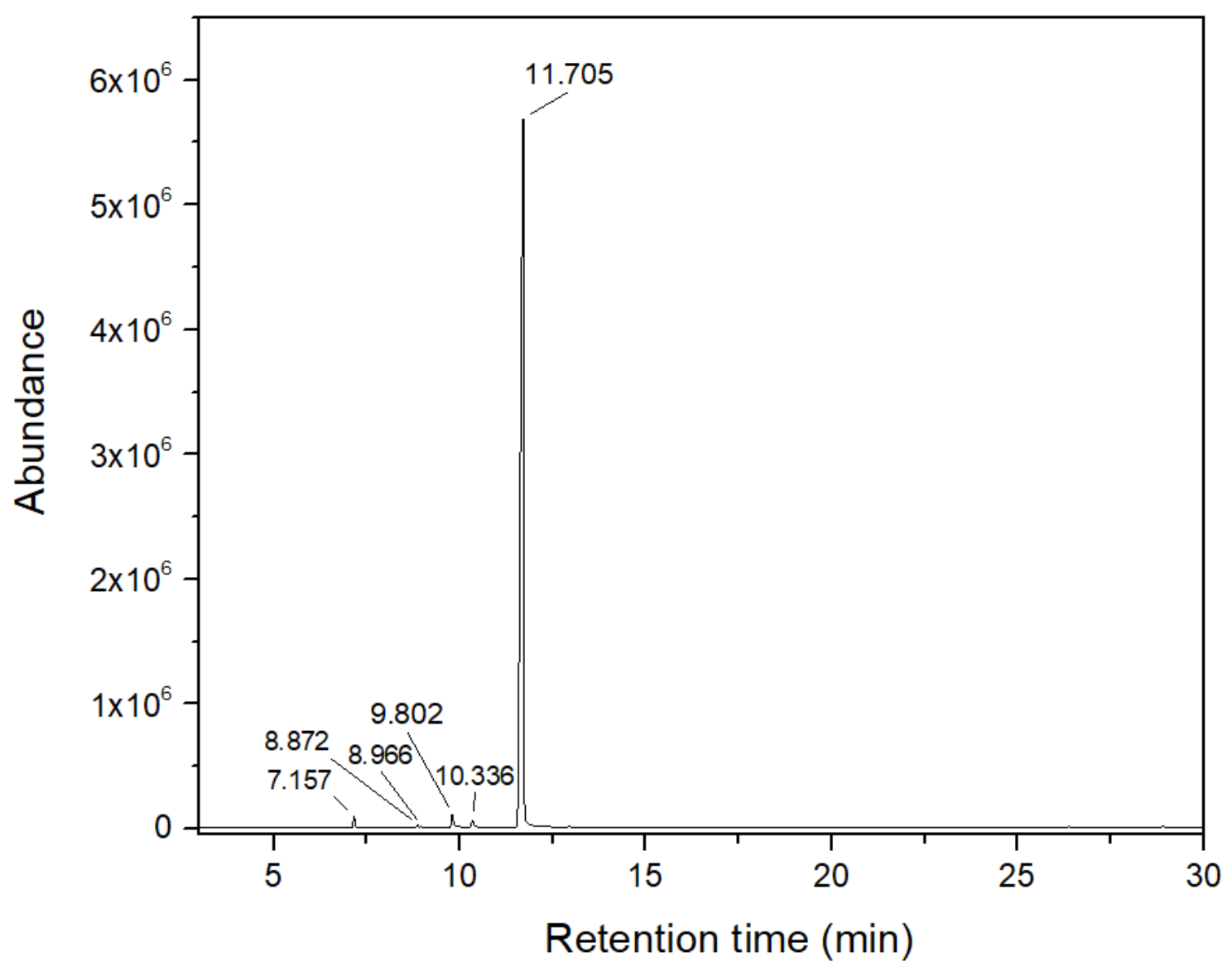

Figure 7. Spectral chromatography of GC-MS.

Table 8. Chemical composition of pomelo essential oil extracted by steam distillation.

\begin{tabular}{cccc}
\hline Peak & Retention Time $(\mathbf{m i n})$ & Compound & Percent \\
\hline 1 & 7.157 & 1 R-a-Pinene & 0.75 \\
2 & 8.861 & Sabinene & 0.19 \\
3 & 8.955 & $\beta$-Pinene & 0.07 \\
4 & 9.802 & $\beta$-Myrcene & 1.31 \\
5 & 10.346 & $\alpha$-Phellandrene & 0.69 \\
6 & 11.705 & D-Limonene & 97.00 \\
\hline
\end{tabular}

The main components in the essential oil were D-Limonene (97.00\%) and $\beta$-Myrcene $(1.31 \%)$, which were considered the predominant components of pomelo peel essential oil. Chen et al. [40] showed that the composition of pomelo essential oil (Citrus grandis) in Taiwan extracted by steam distillation yielded a limonene content of only $87.5 \%$. Dao et al. [16] showed that pomelo (Citrus grandis) essential oil obtained by hydrodistillation contained a high level of limonene (97.1\%) but $\beta$-myrcene was missing from the author's study. The compound, $\beta$-myrcene, is known as a fragrance agent; it is used in food and beverage products. The main reported biological properties of $\beta$-myrcene, such as anxiolytic, antioxidant, anti-aging, anti-inflammatory, and analgesic properties, were previously discussed [41]. Differences in chemical composition or abundance of compounds in essential oils may be due to different extraction techniques. In addition, the composition of essential oils was highly dependent on the growing conditions as well as harvesting time [42]. The presence of different bioactive components determines a wide range of biological activities, typically antibacterial activity, thereby contributing to the quality of the essential oils product. 


\section{Conclusions}

This study performed optimization of the steam distillation process to recover essential oils from pomelo peels and explored kinetics and thermodynamics of the process. The correlation of factors affecting the extraction process is also clearly shown, notably the steam flow rate, which greatly affects the process. The nature of the extraction process is also described through the model of simultaneous washing and unhindered diffusion. Activation energy, thermodynamics, and GC-MS analysis were also presented to show process parameters as well as the quality of essential oil extracted by the steam distillation method. Further studies are expected to further explore the kinetics for other extraction processes to justify the scalability of the extraction process, which contributes to reduction of agricultural waste and enhanced valorization of the pomelo fruit.

Author Contributions: Formal analysis, T.N.T.A. and N.H.T.A.; investigation, T.P.D., T.V.N., T.Y.N.T., X.T.L. and T.N.T.A.; methodology, T.P.D., T.V.N., T.Y.N.T., X.T.L. and N.H.T.A.; resources, L.G.B.; software, T.P.D., T.V.N., T.Y.N.T., X.T.L., T.N.T.A. and L.G.B.; supervision, X.T.L. and L.G.B.; validation, T.P.D., T.V.N., T.Y.N.T., T.N.T.A., N.H.T.A. and L.G.B.; writing-original draft, T.P.D.; writingreview and editing, T.P.D. and L.G.B. All authors have read and agreed to the published version of the manuscript.

Funding: This research was funded by The Youth Incubator for Science and Technology Programe, managed by Youth Development Science and Technology Center-Ho Chi Minh Communist Youth Union and Department of Science and Technology of Ho Chi Minh City, the contract number is “31/2020/HĐ-KHCNT-VU” and APC was funded by Nguyen Tat Thanh University.

Institutional Review Board Statement: Not applicable.

Informed Consent Statement: Not applicable.

Data Availability Statement: The data supporting the research findings of this study are available from the corresponding author on request.

Acknowledgments: The study was supported by The Youth Incubator for Science and Technology Programe, managed by Youth Development Science and Technology Center-Ho Chi Minh Communist Youth Union and Department of Science and Technology of Ho Chi Minh City, the contract number is "31/2020/HĐ-KHCNT-VU”.

Conflicts of Interest: The authors declare no conflict of interest.

\section{References}

1. Burana-osot, J.; Soonthornchareonnon, N.; Chaidedgumjorn, A.; Hosoyama, S.; Toida, T. Determination of Galacturonic Acid from Pomelo Pectin in Term of Galactose by HPAEC with Fluorescence Detection. Carbohydr. Polym. 2010, 81, 461-465. [CrossRef]

2. Dao, T.P.; Tran, T.H.; Nguyen, D.T.; Nguyen, D.C.; Nguyen, D.H.; Hong Le, N.T.; Sy, D.T.; Thanh Huong, N.T.; Minh, B.L. Application of Response Surface Methodology for the Optimization of Essential Oils from Pomelo [Citrus Grandis (L.) Osbeck] Leaves Using Microwave-Assisted Hydrodistillation Method. Asian J. Chem. 2019, 31, 1639-1642. [CrossRef]

3. Tan, Y.M.; Lim, S.H.; Tay, B.Y.; Lee, M.W.; Thian, E.S. Functional Chitosan-Based Grapefruit Seed Extract Composite Films for Applications in Food Packaging Technology. Mater. Res. Bull. 2015, 69, 142-146. [CrossRef]

4. Sugimoto, N.; Tada, A.; Kuroyanagi, M.; Yoneda, Y.; Yun, Y.S.; Kunugi, A.; Sato, K.; Yamazaki, T.; Tanamoto, K. Survey of Synthetic Disinfectants in Grapefruit Seed Extract and Its Compounded Products. J. Food Hyg. Soc. Jpn. 2008, 49, 56-62. [CrossRef]

5. Long, C. Study on technology of supercritical fluid extraction of essential oil from shaddock peel. Beverage Ind. 2007, 7. Available online: https:/ / en.cnki.com.cn/Article_en/CJFDTotal-RYLG200707004.htm (accessed on 18 November 2021).

6. Uysal, B.; Sozmen, F.; Aktas, O.; Oksal, B.S.; Kose, E.O. Essential Oil Composition and Antibacterial Activity of the Grapefruit (Citrus Paradisi. L) Peel Essential Oils Obtained by Solvent-Free Microwave Extraction: Comparison with Hydrodistillation. Int. J. Food Sci. Technol. 2011, 46, 1455-1461. [CrossRef]

7. Darjazi, B.B. Compilation of peel components of Pummelo (Citrus grandis) obtained using cold-press and hydrodistillation method. J. Life Sci. Biomed. 2014, 5, 71-77.

8. Dao, T.P.; Do, H.T.; Le, Q.K.; Gia Phap, N.V.; Bach, L.G.; Muoi, N.V.; Cang, M.H. Kinetic Studies on Extraction of Essential Oil from Lemongrass Leaves (Cymbopogon Citratus) by Steam Distillation Industrial Scale. Asian J. Chem. 2020, 32, 1399-1403. [CrossRef]

9. Tran, T.H.; Ha, L.K.; Nguyen, D.C.; Dao, T.P.; Nhan, L.T.H.; Nguyen, D.H.; Nguyen, T.D.; Vo, D.-V.N.; Tran, Q.T.; Bach, L.G. The Study on Extraction Process and Analysis of Components in Essential Oils of Black Pepper (Piper Nigrum L.) Seeds Harvested in Gia Lai Province, Vietnam. Processes 2019, 7, 56. [CrossRef] 
10. Dao, T.P.; Chinh Nguyen, D.; Hien Tran, T.; Van Thinh, P.; Quang Hieu, V.; Vo Nguyen, D.V.; Duy Nguyen, T.; Giang Bach, L. Modeling and optimization of the orange leaves oil extraction process by microwave-assisted hydro-distillation: The response surface method based on the central composite approach (rsm-ccd model). RJC 2019, 12, 666-676. [CrossRef]

11. Milojević, S.Ž.; Stojanović, T.D.; Palić, R.; Lazić, M.L.; Veljković, V.B. Kinetics of Distillation of Essential Oil from Comminuted Ripe Juniper (Juniperus Communis L.) Berries. Biochem. Eng. 2008, 39, 547-553. [CrossRef]

12. Desai, M.A.; Parikh, J.; De, A.K. Modelling and Optimization Studies on Extraction of Lemongrass Oil from Cymbopogon Flexuosus (Steud.) Wats. Chem. Eng. Res. Des. 2014, 92, 793-803. [CrossRef]

13. Milojevic, S.; Radosavljevic, D.; Pavicevic, V.; Pejanovic, S.; Veljkovic, V. Modeling the Kinetics of Essential Oil Hydrodistillation from Plant Materials. Hem. Ind. 2013, 67, 843-859. [CrossRef]

14. Marković, M.S.; Radosavljević, D.B.; Pavićević, V.P.; Ristić, M.S.; Milojević, S.Ž.; Bošković-Vragolović, N.M.; Veljković, V.B. Influence of Common Juniper Berries Pretreatment on the Essential Oil Yield, Chemical Composition and Extraction Kinetics of Classical and Microwave-Assisted Hydrodistillation. Ind. Crop. Prod. 2018, 122, 402-413. [CrossRef]

15. Marković, M.S.; Milojević, S.Ž.; Bošković-Vragolović, N.M.; Pavićević, V.P.; Babincev, L.M.; Veljković, V.B. A New Kinetic Model for the Common Juniper Essenstial Oil Extraction by Microwave Hydrodistillation. Chin. J. Chem. Eng. 2019, 27, 605-612. [CrossRef]

16. Dao, T.P.; Kha, C.T.; Xuan, P.H.; Tran, T.T. Extraction Process Optimization and Compositional Determination of the Essential Oil from Pomelo (Citrus Grandis L.) Grown in Tien Giang Province, Vietnam. NVEO 2020, 7, 26-33. [CrossRef]

17. Dao, T.P.; Tran, T.H.; Quyen Ngo, T.C.; Kieu Linh, H.T.; Yen Trung, L.N.; Danh, V.T.; Le Ngoc, T.T.; Yen Pham, N.D.; Quan, P.M.; Toan, T.Q. Extraction of Essential Oils from Vietnam's Orange (Citrus Sinensis) Peels by Hydrodistillation: Modeling and Process Optimization. Asian J. Chem. 2019, 31, 2827-2833. [CrossRef]

18. Ngo, T.C.Q.; Dao, T.P.; Tran, T.H.; Le, T.H.N.; Pham, M.Q.; Nguyen, N.H.; Tran, Q.T. Application of Response Surface Methodology in the Process of Extracting Essential Oil from the Calamondin (Citrus Microcarpa) Peels. IOP Conf. Ser. Mater. Sci. Eng. 2020, 736, 022062. [CrossRef]

19. Phat, D.T.; Quyen, N.T.C.; Minh, P.T.H.; Huyen, L.V. Modeling the Kinetics of Essential Oil Hydrodistillation from Vietnamese Ginger (Zingiber Officinale). IOP Conf. Ser. Mater. Sci. Eng. 2020, 991, 012108. [CrossRef]

20. Dao, P.T.; Tran, N.Y.T.; Tran, Q.N.; Bach, G.L.; Lam, T.V. Kinetics of Pilot-Scale Essential Oil Extraction from Pomelo (Citrus Maxima) Peels: Comparison between Linear and Nonlinear Models. Alex. Eng. J. 2021, S1110016821004701. [CrossRef]

21. Alam, P.N.; Husin, H.; Asnawi, T.M. Adisalamun Extraction of Citral Oil from Lemongrass (Cymbopogon Citratus) by Steam-Water Distillation Technique. IOP Conf. Ser. Mater. Sci. Eng. 2018, 345, 012022. [CrossRef]

22. Prasad, D.; Prasad, B.; Prasad, D.; Shetty, P.; Kumar, K. GC-MS Compositional Analysis of Essential Oil of Leaf and Fruit Rind of Citrus Maxima (Burm.) Merr. from Coastal Karnataka, India. J. Appl. Pharm. Sci. 2016, 6, 68-72. [CrossRef]

23. Stanisavljević, I.T.; Lazić, M.L.; Veljković, V.B.; Stojičević, S.S.; Veličković, D.T.; Ristić, M.S. Kinetics of Hydrodistillation and Chemical Composition of Essential Oil from Cherry Laurel (Prunus Laurocerasus L. Var. Serbica Pančić) Leaves. J. Essent. Oil Res. 2010, 22, 564-567. [CrossRef]

24. Pham, T.N.; Nguyen, V.T.; Toan, T.Q.; Cang, M.H.; Bach, L.G.; Van Muoi, N. Effects of Various Processing Parameters on Polyphenols, Flavonoids, and Antioxidant Activities of Codonopsis Javanica Root Extract. Nat. Prod. Commun. 2020, 15, 1934578X2095327. [CrossRef]

25. Tran, T.Y.N.; Dang, T.T.; Do, T.N.; Pham, V.T.; Do, V.L.; Chung, T.P.T.; Nguyen, N.Q.; Tran, B.L.; Le, D.T.; Dao, T.P. Optimization of the Cold Drying Process of Mango (Mangifera Indica L.) Tu Quy Variety by Response Surface Methodology. Food Res. 2021, 5, 386-393. [CrossRef]

26. Rowshan, V.; Bahmanzadegan, A.; Saharkhiz, M.J. Influence of Storage Conditions on the Essential Oil Composition of Thymus Daenensis Celak. Ind. Crops Prod. 2013, 49, 97-101. [CrossRef]

27. Tran, T.H.; Nguyen, H.H.H.; Nguyen, D.C.; Nguyen, T.Q.; Tan, H.; Nhan, L.T.H.; Nguyen, D.H.; Tran, L.D.; Do, S.T.; Nguyen, T.D. Optimization of Microwave-Assisted Extraction of Essential Oil from Vietnamese Basil (Ocimum basilicum L.) Using Response Surface Methodology. Processes 2018, 6, 206. [CrossRef]

28. Hien, T.T.; Nhan, N.P.T.; Trinh, N.D.; Ho, V.T.T.; Bach, L.G. Optimizing the Pomelo Oils Extraction Process by Microwave-Assisted Hydro-Distillation Using Soft Computing Approaches. SSP 2018, 279, 217-221. [CrossRef]

29. Mateus, E.; Lopes, C.; Nogueira, T.; Lourenço, J.; Curto, M. Pilot Steam Distillation of Rosemary (Rosmarinus Officinalis L.) from Portugal. Silva Lusit. 2006, 14, 203-217.

30. Charchari, S.; Hamadi, S. Kinetic Study of Artemisia Judaica L. Essential Oil Steam Distillation. J. Essent. Oil-Bear Plants 2007, 10, 304-309. [CrossRef]

31. Kusuma, H.S.; Mahfud, M. Comparison of kinetic models of oil extraction from sandalwood by microwave-assisted hydrodistillation. Int. Food Res. J. 2017, 24, 1697-1702.

32. Reinoso, B.D.; Muñoz, M.J.G.; González, H.D. Chapter 1-Introduction. In Water Extraction of Bioactive Compounds; González, H.H., Muñoz, M.J.G., Eds.; Elsevier: Amsterdam, The Netherlands, 2017; pp. 1-50. ISBN 9780128093801.

33. Mohamad, M.; Ali, M.W.; Ripin, A.; Ahmad, A. Effect of Extraction Process Parameters on the Yield of Bioactive Compounds from the Roots of Eurycoma Longifolia. J. Teknol. 2013, 60. [CrossRef]

34. Man, H.C.; Hamzah, M.H.; Jamaludin, H.; Abidin, Z.Z. Preliminary Study: Kinetics of Oil Extraction from Citronella Grass by Ohmic Heated Hydro Distillation. APCBEE Procedia 2012, 3, 124-128. [CrossRef] 
35. Agu, C.M.; Agulanna, A.C. Kinetics and Thermodynamics of Oil Extracted from Amaranth. In Nutritional Value of Amaranth; Waisundara, V.Y., Ed.; IntechOpen: London, UK, 2020; ISBN 9781838800833.

36. Chen, Q.; Hu, Z.; Yao, F.Y.-D.; Liang, H. Study of Two-Stage Microwave Extraction of Essential Oil and Pectin from Pomelo Peels. LWT Food Sci. Technol. 2016, 66, 538-545. [CrossRef]

37. Santos, S.B. dos Martins, M.A.; Caneschi, A.L.; Aguilar, P.R.M.; Coimbra, J.S.D.R. Kinetics and Thermodynamics of Oil Extraction from Jatropha Curcas L. Using Ethanol as a Solvent. Int. J. Chem. Eng. 2015, 2015, 1-9. [CrossRef]

38. Abed, K.M.; Kurji, B.M.; Rashid, S.A.; Abdulmajeed, B.A. Kinetics and thermodynamics of peppermint oil extraction from peppermint leaves. IJCPE 2019, 20, 1-6. [CrossRef]

39. Meziane, S.; Kadi, H. Kinetics and Thermodynamics of Oil Extraction from Olive Cake. J. Am. Oil Chem. Soc. 2008, 85, 391-396. [CrossRef]

40. Chen, G.-W.; Lin, Y.-H.; Lin, C.-H.; Jen, H.-C. Antibacterial Activity of Emulsified Pomelo (Citrus Grandis Osbeck) Peel Oil and Water-Soluble Chitosan on Staphylococcus Aureus and Escherichia Coli. Molecules 2018, 23, 840. [CrossRef] [PubMed]

41. Surendran, S.; Qassadi, F.; Surendran, G.; Lilley, D.; Heinrich, M. Myrcene-What Are the Potential Health Benefits of This Flavouring and Aroma Agent? Front. Nutr. 2021, 8, 400. [CrossRef]

42. Baccati, C.; Gibernau, M.; Paoli, M.; Ollitrault, P.; Tomi, F.; Luro, F. Chemical Variability of Peel and Leaf Essential Oils in the Citrus Subgenus Papeda (Swingle) and Few Relatives. Plants 2021, 10, 1117. [CrossRef] 